Article

\title{
Preparation Method of Corn Stalk Fiber Material and Its Performance Investigation in Asphalt Concrete
}

\author{
Zining Chen ${ }^{1}$, Zhiguo Chen ${ }^{2}$, Junyan $\mathrm{Yi}^{1, *}$ and Decheng Feng ${ }^{1, *}$ \\ 1 School of Transportation Science and Engineering, Harbin Institute of Technology, Harbin 150090, China \\ 2 Jilin provincial transport scientific research institute, Changchun 130102, China \\ * Correspondence: yijunyan@hit.edu.cn (J.Y.); fengdecheng@hit.edu.cn (D.F.)
}

Received: 3 July 2019; Accepted: 25 July 2019; Published: 26 July 2019

\begin{abstract}
In this study, a bioresource material, corn stalks, were converted by a combination of physical and chemical methods into a corn stalk fiber material that can be utilized in an asphalt pavement. Firstly, corn stalk fiber was produced with different comminution times, mass fractions of sodium hydroxide solution, reaction times, and reaction temperatures. An orthogonal experimental method was employed to determine the optimal production process. The results show that the optimal comminution time was $3.5 \mathrm{~min}$, and corn stalk should be reacted with a sodium hydroxide solution at $80^{\circ} \mathrm{C}$ for $30 \mathrm{~min}$ to obtain the best corn stalk fiber product. The mass ratios of corn stalk fibers, sodium hydroxide, and water should be 8:1:200. After an evaluation of the physical and mechanical properties of the corn stalk fibers, asphalt binders, and mixtures, it was concluded that this kind of corn stalk fiber can be a good substitute of pavement fiber.
\end{abstract}

Keywords: corn stalk fiber; sodium hydroxide treatment; rind-pith separation; orthogonal experimental method; production process optimization; asphalt pavement material

\section{Introduction}

As China is a large agricultural country, its annual grain output ranks first in the world, and the annual output of cereal stalks as a by-product has reached 800 million tonnes. Among these, the output of corn (i.e., maize) stalks is about 250 million tonnes per year, and with the continuous advances in agricultural science and technology, the production of grain and straw will gradually increase [1].

The effective treatment of stalks represents a serious problem. If stalks are left on a field, roadside, or ditch, they will decompose after prolonged exposure to sun and rain. Large amounts of nutrients will enter surface water systems together with rainwater and cause eutrophication [2]. However, if stalks are used as a fuel for incineration, they will cause intermittent air pollution in the area. The smog that occurs in China is mainly caused by the burning of stalks [3]. Some studies have shown that the combustion of stalks will emit large amounts of $\mathrm{CO}, \mathrm{CO}_{2}$, and $\mathrm{NO}_{2}$, which will lead to a rapid increase in diseases such as those of the respiratory tract [4]. The burning of stalks can also lead to a reduction in soil fertility, which is not conducive to the growth of crops. Studies have shown that the incineration of stalks reduces the soil moisture content, has a tendency to increase the soil $\mathrm{pH}$, and reduces the contents of organic matter, nitrogen, and phosphorus in the soil. This will finally lead to a reduction in crop yields [5].

Outdoor burning is a method that farmers have used to dispose of stalks. However, because of its harmfulness, governments in all countries do not encourage the burning of stalks. At present, many countries have developed corresponding technologies for the utilization of stalks. Among these is the use of stalks as feed after ammonization, which has been widely employed in the United States, Japan, Canada, and Western Europe [6]. The use of stalks in power generation technology is an important 
component of the utilization of straw to generate energy, and this technology has become increasingly mature in countries such as the UK, the Netherlands, and Denmark $[7,8]$.

With the rapid development of the global economy, owing to the increasing traffic load on asphalt pavements, traditional asphalt pavements have been unable to meet people's increasing travel requirements [9]. Thus far, researchers have enhanced the performance of asphalt pavement by adding fibers to asphalt mixtures and have achieved remarkable results. As a kind of high-strength, durable, lightweight, and reinforced functional material, fibers such as lignin fiber and basalt fiber can significantly improve the performance and extend the service life of asphalt pavement [10].

In recent years, plant fibers have been highly valued by researchers [11]. Plant stalks are processed into fiber materials by certain methods [12]. Owing to their desirable physical and mechanical properties, they can be used as functional materials for the production of composite materials. Qin et al. [13] used rice stalk fibers modified with butyl acrylate to make composite materials. Nourbakhsh et al. [14] used corn stalk fibers, reed fibers, and cotton stalk fibers to make resin-reinforced composite materials.

Most researchers use stalk fibers in the production of resin-based composite materials, which are rarely used in asphalt pavements. If corn stalk fiber material can be effectively applied to asphalt pavement, it will have a sustainable impact on society. As an essential crop in agricultural production, the production process of corn also produces a large amount of corn stalks. The recycling of corn stalk will solve the problem of environmental pollution, and the large use of corn stalk fiber in asphalt pavement will also improve the performance of asphalt pavement. Therefore, the application of corn stalk fiber to asphalt pavement will produce very good social and economic benefits. The purpose of this study was to use physical and chemical means to convert corn stalks into fiber materials that are suitable for application in asphalt pavements, so that they can improve the performance of asphalt pavements and also replace certain fibers derived from limited resource, such as basalt fiber.

\section{Materials and Equipment}

\subsection{Corn Stalk}

The corn stalks used in the experiment were obtained from a farm in Dehui City, Jilin Province, northern China. They were undamaged on the surface and were not moldy. Their color was yellow and they were relatively dry. Examples of the corn stalks are shown in Figure 1.

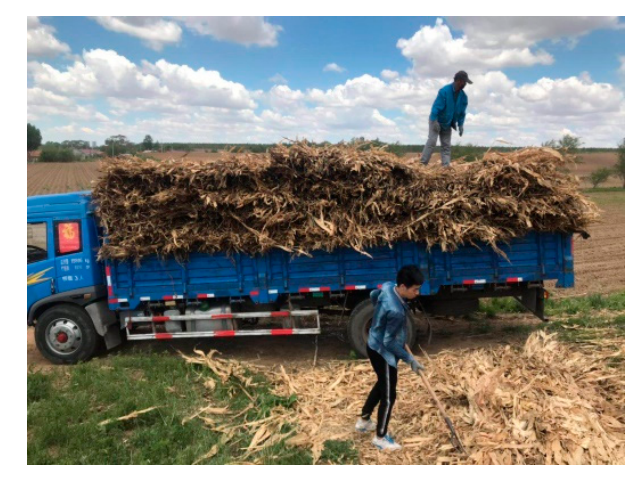

Figure 1. Corn stalks.

\subsection{Fibers Used for Comparison}

After the preparation of the corn stalk fibers, two known fiber materials used in asphalt pavements were selected for performance comparison tests, namely, lignin fiber (Figure 2), produced by Jilin Zhengxiang Company, China, and basalt fiber (Figure 3) from Jilin Tongxin Basalt Technology Co., Ltd., China. The physical properties of the lignin fiber and basalt fiber are listed in Tables 1 and 2, respectively. 


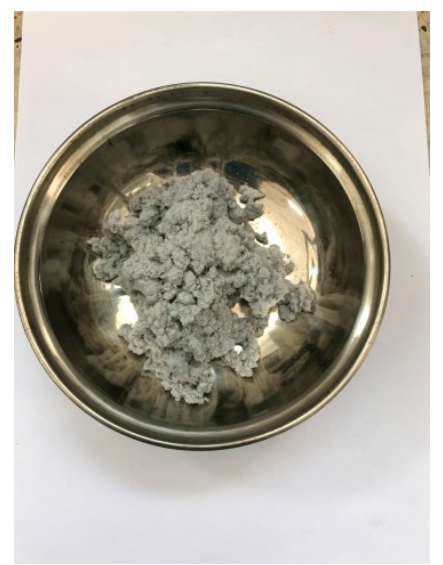

Figure 2. Lignin fiber.

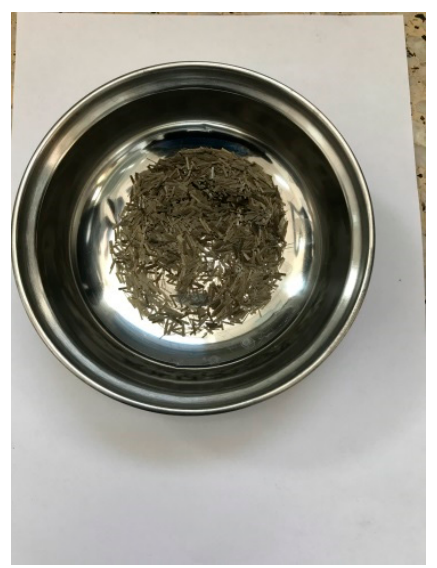

Figure 3. Basalt fiber.

Table 1. Physical properties of lignin fiber.

\begin{tabular}{cccc}
\hline Tested Property & Unit & Value & testing Base \\
\hline Fiber length & $\mathrm{mm}$ & $<5$ & $\mathrm{JT} / \mathrm{T} \mathrm{533-2004}$ \\
Ash content & $\%$ & 18.9 & $\mathrm{JT} / \mathrm{T} \mathrm{533-2004}$ \\
PH & - & 7.8 & $\mathrm{JT} / \mathrm{T} \mathrm{533-2004}$ \\
Oil absorption rate & multiple & 5.3 & $\mathrm{JT} / \mathrm{T} \mathrm{533-2004}$ \\
Mositure content & $\%$ & 2.9 & $\mathrm{JT} / \mathrm{T} 533-2004$ \\
Density & $\mathrm{g} / \mathrm{cm}^{3}$ & 0.536 & $\mathrm{JT} / \mathrm{T} \mathrm{533-2004}$ \\
\hline
\end{tabular}

Table 2. Physical properties of basalt fiber.

\begin{tabular}{cccc}
\hline Tested Property & Unit & Value & testing Base \\
\hline Fiber diameter & $\mu \mathrm{m}$ & 15.72 & $\mathrm{JT} / \mathrm{T} 776.1-2010$ \\
Fiber length & $\mathrm{mm}$ & 7 & $\mathrm{JT} / \mathrm{T} 776.1-2010$ \\
Oil absorption rate & multiple & 2.4 & $\mathrm{JT} / \mathrm{T} 766.1-2010$ \\
Mositure content & $\%$ & 0.2 & $\mathrm{JT} / \mathrm{T} 766.1-2010$ \\
Breaking strength & $\mathrm{MPa}$ & 1612 & $\mathrm{JT} / \mathrm{T} 776.1-2010$ \\
Elongation at break & $\%$ & 2.2 & $\mathrm{JT} / \mathrm{T} 776.1-2010$ \\
Density & $\mathrm{g} / \mathrm{cm}^{3}$ & 2.63 & $\mathrm{JT} / \mathrm{T} 776.1-2010$ \\
Elastic Modulus & $\mathrm{MPa}$ & $102.9 \times 10^{3}$ & $\mathrm{JT} / \mathrm{T} 776.1-2010$ \\
Heat resistance, fracture strength retention & $\%$ & 96.1 & $\mathrm{JT} / \mathrm{T} 776.1-2010$ \\
\hline
\end{tabular}




\subsection{Asphalt}

The asphalt type of AH-90, produced by the CNPC Liaohe Petrochemical was used for fibers asphalt in the experiments, and the asphalt type of SBS-modified asphalt was used for fibers asphalt mixtures in the experiments. The basic physical properties of asphalts were measured following Chinese specification (JTG E20-2011), and are presented in Table 3.

Table 3. Physical properties of asphalts.

\begin{tabular}{cccc}
\hline \multicolumn{1}{c}{ Asphalt Type } & & AH-90 Asphalt & SBS-Modified Asphalt \\
\hline Tested Property & Unit & Value & Value \\
\hline Penetration $\left(25^{\circ} \mathrm{C}\right)$ & $0.1 \mathrm{~mm}$ & 83.0 & 63.0 \\
Softening point & ${ }^{\circ} \mathrm{C}$ & 44.0 & 72.5 \\
Ductility & $\mathrm{cm}$ & $>100\left(10^{\circ} \mathrm{C}\right)$ & $55\left(5^{\circ} \mathrm{C}\right)$ \\
Ductility $\left(15^{\circ} \mathrm{C}\right)$ & $\mathrm{cm}$ & $>100$ & - \\
Wax content & $\%$ & 2.0 & - \\
Flash point & ${ }^{\circ} \mathrm{C}$ & 276 & - \\
Burning point & ${ }^{\circ} \mathrm{C}$ & 285 & 99.5 \\
Solubility & $\%$ & 99.8 & 1.015 \\
Density $\left(15^{\circ} \mathrm{C}\right)$ & $\mathrm{g} / \mathrm{cm}^{3}$ & 1.007 & $2.4\left(135^{\circ} \mathrm{C}\right)$ \\
Dynamic viscosity & $\mathrm{Pa} . \mathrm{S}$ & $211\left(60^{\circ} \mathrm{C}\right)$ &
\end{tabular}

\subsection{Aggregate}

The coarse and fine aggregates were produced by one stone factory in Siping City, Jilin Province, and the fillers were derived from fine limestone. The grading of SMA-13 asphalt mixture is shown in Table 4.

Table 4. Percentage of mass passing through each mesh of SMA-13 asphalt mixture.

\begin{tabular}{ccccccccccc}
\hline Screen Size $(\mathbf{m m})$ & $\mathbf{1 6}$ & $\mathbf{1 3 . 2}$ & $\mathbf{9 . 5}$ & $\mathbf{4 . 7 5}$ & $\mathbf{2 . 3 6}$ & $\mathbf{1 . 1 8}$ & $\mathbf{0 . 6}$ & $\mathbf{0 . 3}$ & $\mathbf{0 . 1 5}$ & $\mathbf{0 . 0 7 5}$ \\
\hline Design level $(\%)$ & 100 & 91 & 67.4 & 30.7 & 23.5 & 20.2 & 16.8 & 15 & 13.9 & 10.3 \\
\hline Normative median $(\%)$ & 100 & 95 & 62.5 & 27 & 20.5 & 19 & 16 & 13 & 12 & 10 \\
\hline Specification range $(\%)$ & 100 & $90 \sim 100$ & $50 \sim 75$ & $20 \sim 34$ & $15 \sim 26$ & $14 \sim 24$ & $12 \sim 20$ & $10 \sim 16$ & $9 \sim 15$ & $8 \sim 12$ \\
\hline
\end{tabular}

\section{Experimental Procedures}

\subsection{Preparation of Corn Stalk Fibers}

Corn stalks are composed of rind and pith. The pith of corn stalks is rich in protein, fat, hemicellulose, and sugar [15], whereas the main components of corn stalk rind are cellulose and lignin, which have high strength and toughness [16]. Corn stalk rind is used for the preparation of corn stalk fiber-based composite materials [17]. Because the pith of corn stalks is loose and has poor strength, it must be removed when preparing corn stalk fibers. Otherwise, it is difficult to achieve suitable mechanical properties.

Firstly, selected corn stalks were subjected to a rind-pith separation process using a rind-pith separation instrument (Figure 4) [18], and then the corn stalk rind that was obtained was washed with water. Next, the cleaned corn stalk rind was dried in an oven to a constant weight at a temperature of $70{ }^{\circ} \mathrm{C}$. An example of the corn stalk rind is shown in Figure 5. 


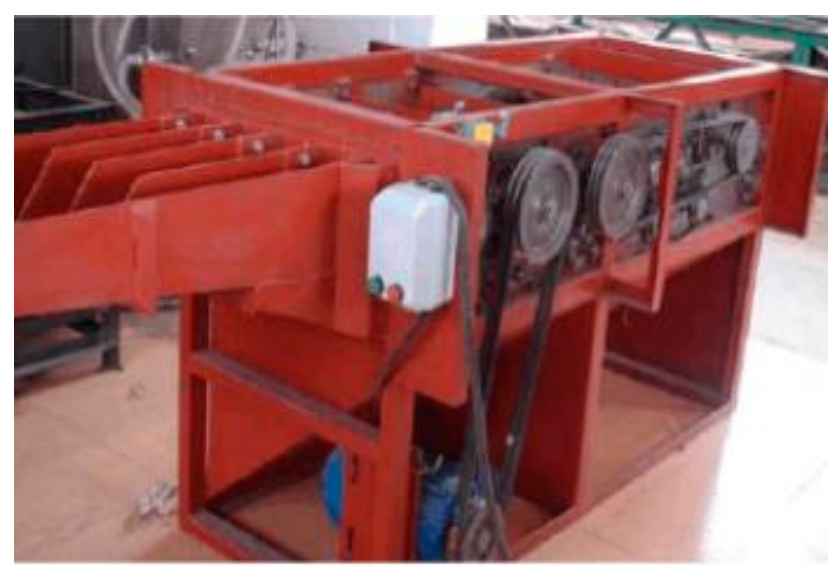

Figure 4. Equipment used for the separation of the rind and pith of corn stalks.

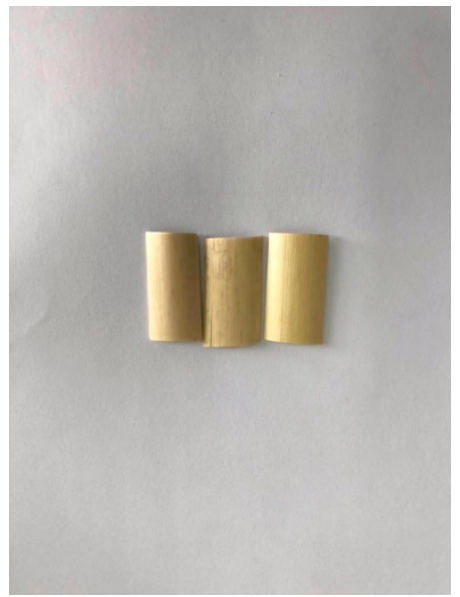

(a)

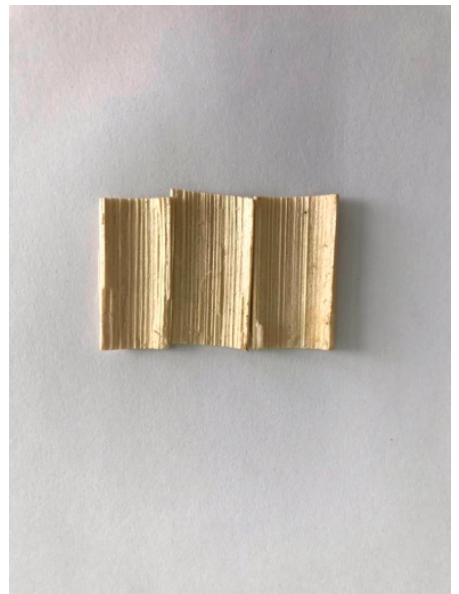

(b)

Figure 5. Corn stalk rind: (a) exterior and (b) interior.

The dried corn stalk rind was cut into strips with a size of $0.5-1.5 \times 3-5 \mathrm{~cm}$, and then crushed using a WKF250 crusher (Figure 6). Next, $50 \mathrm{~g}$ comminuted corn stalk fibers were weighed and placed in a high-speed multifunction crusher (Figure 7) for further comminution for a fixed time.

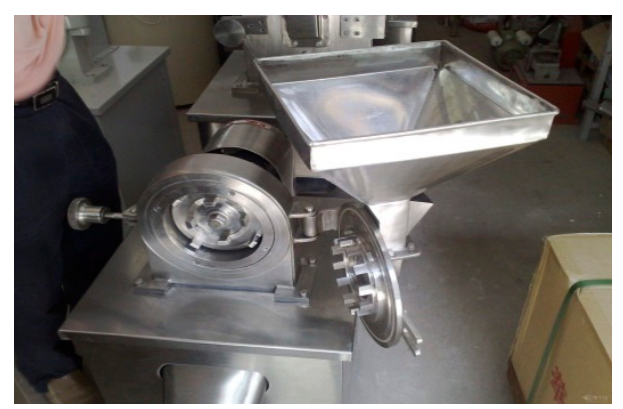

Figure 6. WKF-250 crusher. 


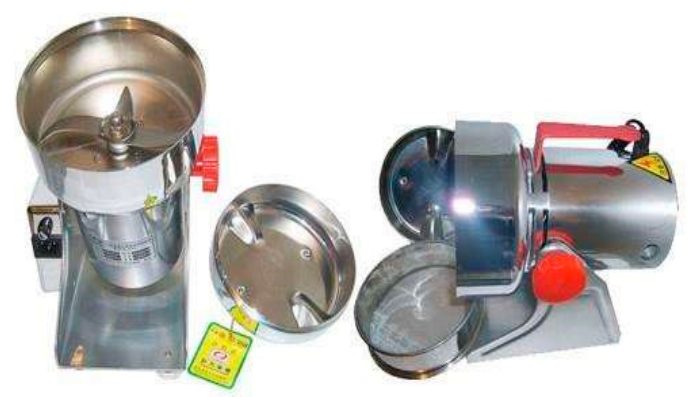

Figure 7. High-speed multi-functional crusher.

A $40 \mathrm{~g}$ sample of the final comminuted corn stalk fibers was immersed in $1000 \mathrm{~mL}$ sodium hydroxide solution with a constant concentration by mass [19], and the reaction between the fibers and sodium hydroxide was carried out with a magnetic stirrer (Figure 8) at a rotational speed of $2000 \mathrm{rpm}$ for a fixed time at a constant temperature. Particles of a sodium hydroxide reagent (Figure 9) were used during the preparation of the corn stalk fibers. These particles were white, transparent, granular, and highly corrosive. The sodium hydroxide content in the reagent was not less than $98.0 \%$. After the reaction was completed, the reaction mixture was rinsed with a large amount of deionized water, and the product was finally dried at a temperature of $110^{\circ} \mathrm{C}$ in an oven to a constant weight to obtain corn stalk fibers suitable for asphalt pavement. The physical and chemical processing of corn stalk fiber is shown in Figure 10.

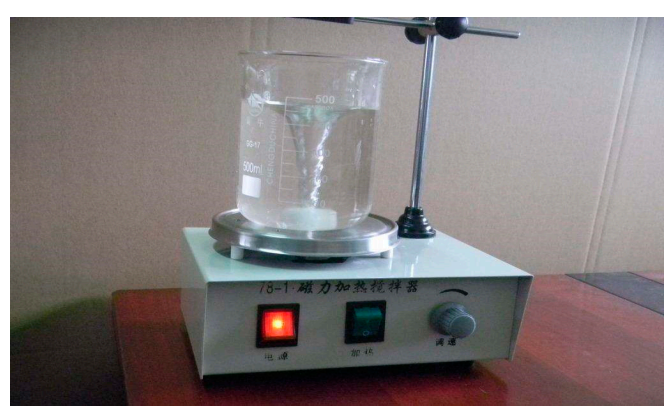

Figure 8. Constant-temperature magnetic stirrer.

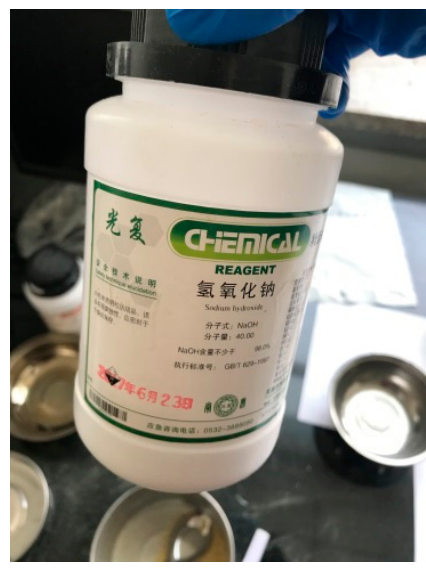

Figure 9. Chemical reagent. 

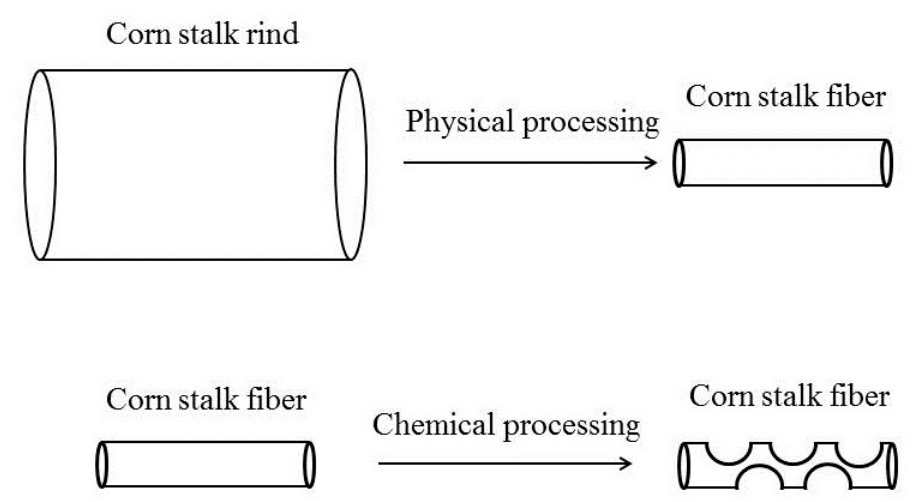

Cellulose, hemicellulose, lignin, pectin, fat Cellulose, hemicellulose, lignin

Figure 10. The physical and chemical processing of corn stalk fiber.

In this research, different values of the following reaction parameters were used: the time used for comminution by the high-speed multifunctional crusher, the mass of the sodium hydroxide reagent, the reaction temperature, and the reaction time. The values of the respective parameters are given in Table 5, and the experimental plan in terms of the combinations of these parameters used is given in Table 6.

Table 5. Specific values of different levels of different parameters.

\begin{tabular}{ccccc}
\hline Level & Parameter A & Parameter B & Parameter C & Parameter D \\
\hline & $\begin{array}{c}\text { Final comminution } \\
\text { time }(\min )\end{array}$ & $\begin{array}{c}\text { Mass of the sodium } \\
\text { hydroxide reagent }(\mathrm{g})\end{array}$ & $\begin{array}{c}\text { Reaction } \\
\text { temperature }\left({ }^{\circ} \mathrm{C}\right)\end{array}$ & $\begin{array}{c}\text { Reaction time }(\mathrm{min}) \\
1\end{array}$ \\
3 & 3.5 & 2.5 & 60 & 15 \\
2 & 4 & 5 & 70 & 30 \\
3 & 10 & 80 & 45 \\
4 & 20 & 90 & 60 \\
\hline
\end{tabular}

Table 6. Experimental plan.

\begin{tabular}{ccccc}
\hline Experiment No. & Levels & & & \\
\hline 1 & Parameter A & Parameter B & Parameter C & Parameter D \\
2 & 1 & 2 & 3 & 2 \\
3 & 2 & 2 & 3 & 2 \\
4 & 3 & 2 & 3 & 2 \\
5 & 2 & 1 & 3 & 2 \\
6 & 2 & 3 & 3 & 2 \\
7 & 2 & 4 & 4 & 2 \\
8 & 2 & 2 & 1 & 2 \\
9 & 2 & 2 & 2 & 2 \\
10 & 2 & 2 & 4 & 1 \\
11 & 2 & 2 & 3 & 3 \\
12 & 2 & 2 & 3 & 4 \\
\hline
\end{tabular}

Depending on the different combinations of parameters, nine kinds of corn stalk fibers were prepared, which were used in oil absorption tests to determine an optimal production plan. The relevant performance tests on the fibers as part of this optimal production plan also relate to the Chinese transportation industry standard "fiber stabilizer for asphalt pavement" (which has not yet been issued and is only at the stage of solicitation of comments), in which fiber performance tests include oil absorption, screening and particle size, scanning electron microscopy, moisture content, heat resistance, moisture absorption, and density tests. 


\subsection{Oil Absorption Test}

The fiber oil absorption test used for traditional asphalt pavement cannot be applied to corn stalk fibers because their size is relatively small and the screen used cannot hold all the fibers during the vibration step. Therefore, an oil absorption test was used to macroscopically determine the oil absorption capacity of corn stalk fibers prepared under different conditions [20]. The test process was as follows.

A $0.1 \mathrm{~g}$ sample of fibers was weighed and placed in a stainless steel screen with a known weight, and then placed in a $1000 \mathrm{~mL}$ beaker containing $400 \mathrm{~mL}$ diesel at room temperature. After oil absorption for $30 \mathrm{~min}$, the fiber material was removed and drained for $5 \mathrm{~min}$. The mass of the material was measured again, and the oil absorption ratio of the material by weight was calculated on the basis of the weight change. All the experiments were repeated three times under the same conditions, and the average data were taken as the calculation results. The following equation was used to calculate the oil absorption ratio of the material by weight:

$$
Q=\frac{m_{w}-m_{i}}{m_{i}}
$$

where $Q$ is the oil absorption ratio of the material by weight, $\mathrm{m}_{\mathrm{w}}$ is the weight of the material after oil absorption, and $\mathrm{m}_{\mathrm{i}}$ is the initial weight of the material.

\subsection{Screening and Particle Size Analysis}

Depending on the preparation process of corn stalk fibers, their diameter is not fixed. Therefore, via a screening test and laser particle size test on a batch of fiber samples, the diameter distribution of the fibers was measured as follows.

Fiber materials were dried and dispersed, and fibers were accurately weighed and placed in analytical sieves. The cap was covered, and the fibers were sieved with a special brush for $10 \mathrm{~min}$. Finally, the remaining masses of fibers in the various sieves were calculated using the following equation:

$$
P_{X}=\frac{m_{w}}{m_{0}} \times 100
$$

where $P_{X}$ is the percentage of the sieve fractions at a particular screening level, $\mathrm{m}_{\mathrm{x}}$ is the weight of fibers at that screening level, and $\mathrm{m}_{0}$ is the total weight of the fibers.

The particle sizes of corn stalk fibers were determined using a Mastersizer 2000 laser particle size analyzer, which was manufactured by Malvern, UK.

\subsection{Scanning Electron Microscopy Test}

In this experiment, scanning electron microscopy was used to characterize the micromorphology of corn stalk fibers before and after treatment with the sodium hydroxide solution. In addition, the morphological changes were observed under different magnifications. The method of sample preparation was as follows: the most macroscopically similar fibers in a sample were selected and pasted directly onto conductive adhesive tape to ensure that the fibers were completely connected to the conductive metal. Then the surfaces of the sample were sprayed with gold for $10 \mathrm{~min}$ for testing.

\subsection{Density Test}

In the density test, a certain quantity of fibers were selected, dried in an oven at $60 \pm 5^{\circ} \mathrm{C}$ for $2 \mathrm{~h}$, and cooled to room temperature in a desiccator until used. The weight of a dry pycnometer was measured, and the fibers were placed in the pycnometer to weigh them as follows. Water was poured into the pycnometer until the fibers were completely immersed. The pycnometer was placed in a desiccator and vacuumed to remove air bubbles. The liquid continued to fill the pycnometer, water on the outer wall of the pycnometer was wiped off, and the pycnometer, water, and fibers were 
weighed as follows. The water and fibers in the pycnometer were then emptied, and the pycnometer was dried, filled with water, and vacuumed in a desiccator to remove air bubbles. Finally, water on the outer wall of the pycnometer was wiped off, and the pycnometer and water were weighed. Because the liquid was water, the value of the liquid density $\rho \mathrm{L}$ was $0.9975 \mathrm{~g} / \mathrm{cm} 3$. The fiber density was calculated as follows:

$$
\rho=\frac{m_{2}}{m_{3}-m_{4}} \rho_{L}
$$

where $\rho$ is the density of the fibers $\left(\mathrm{g} / \mathrm{cm}_{2}\right), \mathrm{m}_{2}$ is the weight of the fibers, $\mathrm{m}_{3}$ is the weight of the pycnometer, water, and fibers, and $\mathrm{m}_{4}$ is the weight of the pycnometer and water.

\subsection{Thermal Stability Test and Differential Thermogravimetric Analysis}

Because the asphalt mixture was subjected to high-temperature conditions in the mixing process, this imposed certain requirements on the thermal stability of the fiber material. The thermal stability of the fibers was determined by measuring the percentage mass loss at high temperatures via thermogravimetric analysis. The test process was as follows.

After an oven was preheated to $105 \pm 5^{\circ} \mathrm{C}$, fiber materials and a crucible were placed on a porcelain plate, dried in the oven at $105 \pm 5^{\circ} \mathrm{C}$ for $2 \mathrm{~h}$, and cooled in a desiccator for at least $30 \mathrm{~min}$. Then, the oven was preheated to $210 \pm 5^{\circ} \mathrm{C}$. The crucible was weighed, and then a $10 \pm 0.1 \mathrm{~g}$ fiber sample was weighed in the crucible. Next, the crucible (including the fibers) was placed in the oven at $210 \pm 5{ }^{\circ} \mathrm{C}$ for $1 \mathrm{~h} \pm 1 \mathrm{~min}$, and it was observed whether the fibers were burning. Finally, the crucible (including the fibers) was removed and put in a desiccator to cool it. The crucible and fibers were weighed. The mass loss was calculated by the following equation:

$$
A C=\frac{m_{1}-m_{2}}{m_{0}} \times 100
$$

where $A C$ is the weight loss $(\%), \mathrm{m}_{0}$ is the weight of the fibers, $\mathrm{m}_{1}$ is the weight of the crucible and fibers, and $\mathrm{m}_{2}$ is the weight of the crucible.

An STA 449C TG-DTA/DSC integrated thermal analyzer produced by Netzsch, Germany, was used for thermogravimetric analysis of corn stalk fibers before and after treatment with the sodium hydroxide solution. During the analysis, the heating rate was $10^{\circ} \mathrm{C} / \mathrm{min}$ in a nitrogen atmosphere, the test temperature range was $10-600^{\circ} \mathrm{C}$, and the weight of the sample was about $15 \mathrm{mg}$.

\subsection{Water Content and Moisture Absorption Test}

The incorporation of fibers into the asphalt mixture plays a major role in the adsorption behavior of asphalt. If the fibers themselves have a high water content, they will affect the performance of the fiber/asphalt mixture. Therefore, the moisture content and hygroscopicity of the fibers need to be determined. The test process was as follows.

A porcelain plate was weighed on a scale, and then a $10.0 \pm 0.1 \mathrm{~g}$ fiber sample was placed on the porcelain plate to be weighed. The porcelain plate (including the fibers) was placed in an oven and heated at $105 \pm 5^{\circ} \mathrm{C}$ for $2 \mathrm{~h}$, and then removed and placed in a desiccator to cool. Finally, the weight of the porcelain plate (including the fibers) was measured. The water content of the fibers was calculated as follows:

$$
W C=\frac{\left(m_{0}-m_{1}+m_{2}\right)}{m_{1}-m_{2}} \times 100
$$

where $W C$ is the moisture content of the fibers $(\%), \mathrm{m}_{0}$ is the weight of the fibers, $m_{1}$ is the weight of the porcelain plate (including the fibers) after heating, and $\mathrm{m}_{2}$ is the weight of the porcelain plate.

The hygroscopicity of a fiber can be expressed by the change in the weight of the fiber before and after absorbing water. In the test, a certain amount of fibers were weighed and placed in a beaker. The mass of the fibers and beaker was measured. The beaker with the fibers was placed in a moisture 
box at a relative humidity of $90 \%$ and a temperature of $20^{\circ} \mathrm{C}$. After $24 \mathrm{~h}$, the changes in the weight of the fibers were measured. The moisture absorption rate of the fibers was calculated as follows:

$$
M A=\frac{m_{2}-m_{1}}{m_{0}} \times 100
$$

where $M A$ is the moisture absorption rate of the fibers (\%), $m_{0}$ is the weight of the fibers, $\mathrm{m}_{1}$ is the weight of the beaker (including the fibers), and $\mathrm{m}_{2}$ is the weight of the beaker (including the fibers) after $24 \mathrm{~h}$.

\subsection{Fiber Asphalt Performance Test}

Corn stalk fibers, lignin fibers, and basalt fibers were respectively blended into AH-90 asphalt in certain mass ratios (Table 7), and the fibers were uniformly mixed at a temperature of $145{ }^{\circ} \mathrm{C}$ using a high-speed shearing machine. The dynamic shear rheometer (DSR) test can be used to assess the performance of fiber asphalt at high temperatures.

In the Superpave specification, the parameter $G^{*} / \sin \delta$ (where $G^{*}$ is the absolute value of the complex modulus, and $\delta$ is the phase angle) from the DSR test is used to account for the contribution of fiber asphalt to the rutting resistance of mixtures, and it is therefore also known as the rutting factor. In this test, the strain level was $12 \%$, the angular frequency was $10 \mathrm{rad} / \mathrm{s}$, and the test temperatures were $64^{\circ} \mathrm{C}$, $70{ }^{\circ} \mathrm{C}$, and $76^{\circ} \mathrm{C}$.

Table 7. Mass ratios of the three kinds of fibers.

\begin{tabular}{ccc}
\hline No. & Fiber Type & Mass Ratio in Asphalt (\%) \\
\hline 1 & Corn stalk fiber & 2 \\
2 & Corn stalk fiber & 4 \\
3 & Corn stalk fiber & 6 \\
4 & Corn stalk fiber & 8 \\
5 & Corn stalk fiber & 10 \\
6 & Lignin fiber & 1 \\
7 & Lignin fiber & 1.5 \\
8 & Lignin fiber & 2 \\
9 & Basalt fiber & 1 \\
10 & Basalt fiber & 1.5 \\
11 & Basalt fiber & 2 \\
12 & Basalt fiber & 2.5 \\
\hline
\end{tabular}

\subsection{Fiber Asphalt Mixtures Performance Test}

According to the design method of SMA-13 asphalt mixture in the Test Procedure for Highway Engineering Asphalt and Asphalt Mixture (JTG E20-2011), the Marshall test was carried out, and the road performance of fibers asphalt mixtures were tested on this basis. These asphalt mixtures include those SMA-13 asphalt mixtures that do not participate in fiber, SMA-13 asphalt mixtures that participate in $0.3 \%$ lignin fibers, and SMA-13 asphalt mixtures that participate in $0.3 \%, 0.6 \%$, and $0.9 \%$ corn stalk fibers.

The high temperature performance of the SMA-13 asphalt mixture was evaluated by the Marshall test. The Marshall test was used to determine the failure load and deformation resistance of asphalt mixture specimens. The asphalt mixture was prepared into a cylindrical test piece of a predetermined size, and the test piece was arranged in two semicircular pressed molds during the test, so that the test piece was subjected to certain lateral restrictions. The main mechanical indexes were stable of Marshall $(\mathrm{kN})$ and flow value $(0.1 \mathrm{~mm})$.

The low-temperature performance of the SMA-13 asphalt mixture was evaluated by the indirect tensile test. The splitting test was to load the asphalt mixture by loading the bead to obtain the splitting 
strength of the asphalt mixture through the sensor and LVDT. The mechanical index was splitting strength $(\mathrm{kN})$.

The water stability of The SMA-13 asphalt mixture was evaluated by the Immersion Marshall test. The Immersion Marshall test was to divide the Marshall Test pieces into two groups. One group was tested for Marshall Stability after being maintained for 0.5 hours in a $60^{\circ} \mathrm{C}$ water bath. Another group was tested for Marshall Stability after 48 hours of constant temperature maintenance in a $60^{\circ} \mathrm{C}$ water bath. Finally, the ratio of the two was calculated, which is the residual stability.

\section{Results and Discussions}

In order to have a better understanding of the properties of the prepared corn stalk fiber products and to optimize the production process, the detailed test results and corresponding analyses are shown in this section.

\subsection{Optimization of the Production Process}

In order to investigate the influence of physical and chemical treatment on the oil absorption performance of the corn stalk fibers, the comminution time for the physical treatment in the high-speed multifunctional crusher was selected to be $3,3.5$, or $4 \mathrm{~min}$. In the chemical modification of corn stalk fibers, sodium hydroxide is commonly used for pretreatment. In these experiments, the mass fraction of the sodium hydroxide solution was $0.25 \%, 0.5 \%, 1 \%$, or $2 \%$, the reaction temperature was $60{ }^{\circ} \mathrm{C}, 70{ }^{\circ} \mathrm{C}, 80^{\circ} \mathrm{C}$, or $90^{\circ} \mathrm{C}$, and the reaction time was $15,30,45$, or $60 \mathrm{~min}$. The diesel absorption performance of the treated corn stalk fibers is shown in Figure 10.

When the comminution times in the high-speed multifunctional crusher were $3,3.5$, and $4 \mathrm{~min}$, the absorption capacity of the pretreated corn stalk fibers for diesel oil was 29.07, 30.37, and $28.6 \mathrm{~g} / \mathrm{g}$, respectively, which represents an initial increase and then a decrease. As the reaction temperature used in the pretreatment increased, the oil absorption performance of the corn stalk fibers exhibited an increasing trend and reached a peak capacity of $30.37 \mathrm{~g} / \mathrm{g}$ at $80^{\circ} \mathrm{C}$, from which point it started to decrease. As can be seen from Figure 11c, when the mass fraction of the sodium hydroxide solution was $0.25 \%, 0.5 \%, 1 \%$, and $2 \%$, the oil absorption capacity of the pretreated corn stalk fibers was $26.67,30.37$, 28.7 , and $27.23 \mathrm{~g} / \mathrm{g}$, respectively. It can be seen that at a mass fraction of the solution of $0.5 \%$, the oil absorption performance of the corn straw fibers was the highest (capacity of $30.37 \mathrm{~g} / \mathrm{g}$ ). Figure $11 \mathrm{~d}$ shows that the effect of the pretreatment reaction time on the oil absorption capacity of the corn stalk fibers was similar to the effect of the mass fraction of the solution. When the reaction time was $30 \mathrm{~min}$, the oil absorption capacity of the straw fibers was the highest $(30.37 \mathrm{~g} / \mathrm{g})$, after which it displayed a downward trend.

By the pretreatment of corn stalk fibers under different conditions, corn stalk fibers with different oil absorption capacities were obtained. After comparative analysis, the pretreated corn stalk fibers displayed the best oil absorption performance when the comminution time was $3.5 \mathrm{~min}$, the mass fraction of the sodium hydroxide solution was $0.5 \%$, the reaction temperature was $80^{\circ} \mathrm{C}$, and the reaction time was $30 \mathrm{~min}$.

The crushing time affects the thickness of the corn stalk fiber, and the temperature and sodium hydroxide concentration affect the internal voids and surface roughness of the corn stalk fiber. Next, the performance of the corn stalk fibers prepared using the optimal combination of parameters was tested. 


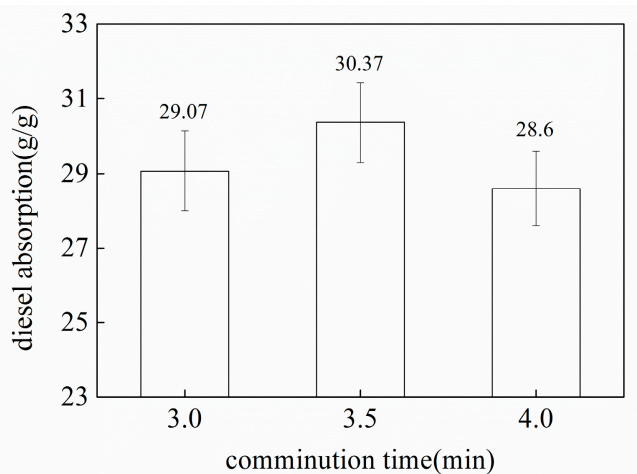

(a)

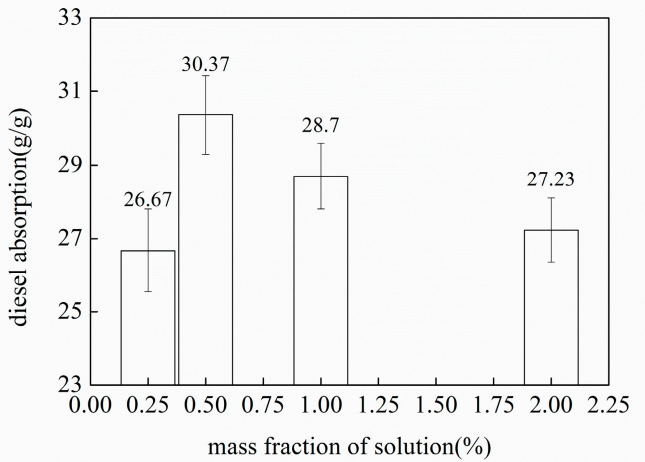

(c)

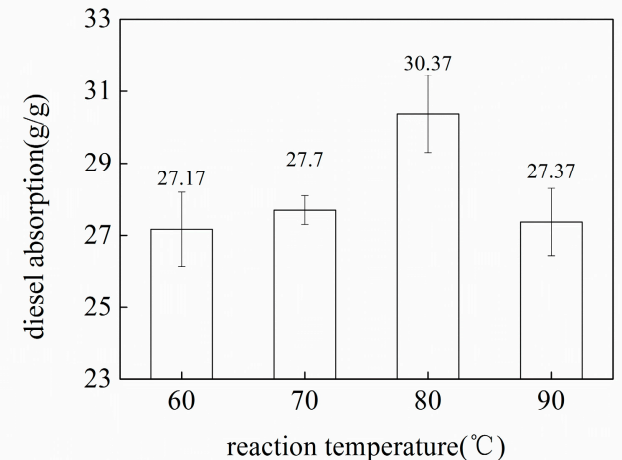

(b)

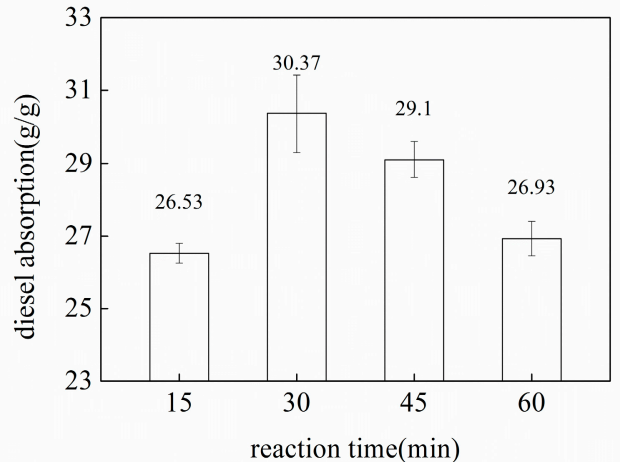

(d)

Figure 11. Effect of pretreatment of corn stalk fibers on their oil absorption property: (a) effect of comminution time (reaction temperature $80{ }^{\circ} \mathrm{C}$; mass fraction of solution $0.5 \%$; reaction time $30 \mathrm{~min}$ ); (b) effect of reaction temperature (comminution time $3.5 \mathrm{~min}$; mass fraction of solution $0.5 \%$; reaction time $30 \mathrm{~min}$ ); (c) effect of mass fraction of solution (comminution time $3.5 \mathrm{~min}$; reaction temperature $80^{\circ} \mathrm{C}$; reaction time $30 \mathrm{~min}$ ); and $(\mathbf{d})$ effect of reaction time (comminution time $3.5 \mathrm{~min}$; reaction temperature $80{ }^{\circ} \mathrm{C}$; mass fraction of solution $0.5 \%$ ).

\subsection{Screening and Particle Size Analysis}

In an asphalt pavement material, the length and diameter of the fiber material used as an additive will directly affect the strength of the asphalt mixture and its workability during construction mixing [21]. The percentages of different types of fiber in different screening size ranges are shown in Table 8. The results show that the corn stalk fibers were crude before comminution, and the percentage of fibers of which the diameters were in the range of $0.875-0.425 \mu \mathrm{m}$ was $26.2 \%$. The diameters of most fibers were concentrated in the range between 0.425 and $0.180 \mu \mathrm{m}(61.0 \%)$. Roughly one-eighth $(12.8 \%)$ of the fibers had diameters of less than $0.180 \mu \mathrm{m}$. After comminution, the diameters of the fibers were all less than $0.425 \mu \mathrm{m}$ and were mainly distributed in the ranges of $0.425-0.180 \mu \mathrm{m}$ and less than $0.106 \mu \mathrm{m}$; the percentages in these two ranges were almost identical. After chemical treatment, the overall diameters of the fibers increased in comparison with those not subjected to chemical treatment. Specifically, the percentage of fibers with a diameter of $0.425-0.180 \mu \mathrm{m}$ increased by $15.9 \%$, the percentage of fibers with a diameter in the range of $0.180-0.106 \mu \mathrm{m}$ increased by $22.8 \%$, and the percentage of fibers with a diameter in the range of less than $0.106 \mu \mathrm{m}$ decreased by $38.4 \%$. This is because after the chemical treatment some of the small-diameter fibers were lost during the cleaning of the fibers using a $50 \mu \mathrm{m}$ mesh.

Because the operating principle of a laser particle size analyzer involves converting the dimensions of a nonspherical material into those of a spherical material and calculating the particle diameter, the diameters of the corn stalk fibers could not be analyzed to a great extent from the fiber size distribution curve in Figure 12. It can be seen from Figure 12 that among fibers with diameters of less than $50 \mu \mathrm{m}$, the amount of chemically treated fibers was significantly less than that of untreated fibers, 
because some fibers with small particle sizes were lost during the cleaning process after the chemical treatment. It can be seen from Figure 12 that the chemically treated fibers had a slightly larger particle size than the untreated fibers. This is because the operating principle of a laser particle size analyzer involves using laser irradiation to measure fibers, and, after the chemical treatment, the corn stalk fibers became rough, which resulted in a larger particle size according to calculations based on the instrumental measurements.

Table 8. Percentages of fibers in different screening size ranges.

\begin{tabular}{cccc}
\hline \multirow{2}{*}{ Screening Size Range $(\boldsymbol{\mu m})$} & \multicolumn{3}{c}{ Fiber Type } \\
\cline { 2 - 4 } & \multicolumn{3}{c}{ Corn Stalk Fibers } \\
\hline & No comminution $(\%)$ & Comminution $(\%)$ & $\begin{array}{c}\text { Comminution and } \\
\text { chemical treatment }(\%)\end{array}$ \\
\hline $0.875-0.425$ & 26.2 & 0 & 0 \\
$0.425-0.180$ & 61.0 & 40.3 & 46.7 \\
$0.180-0.106$ & 6.5 & 20.1 & 24.7 \\
$>0.106$ & 6.3 & 39.6 & 28.6 \\
\hline
\end{tabular}

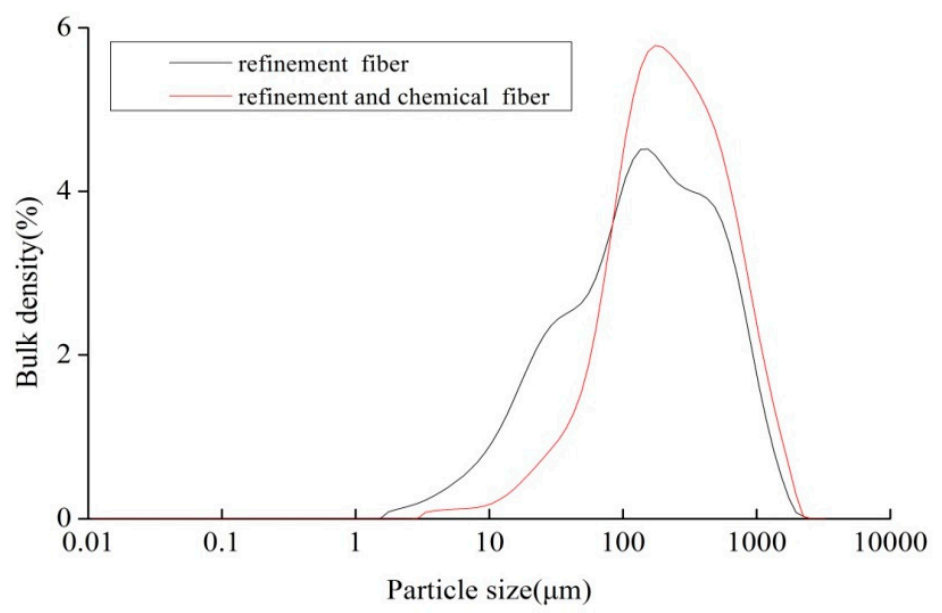

Figure 12. Fiber size distribution curve.

\subsection{Micromorphology of Fibers}

It can be seen from Figure 13 that the surface morphology of the untreated corn stalk fibers was relatively smooth and had a continuous layer structure. However, it can be seen from Figure 14 that after chemical treatment with the sodium hydroxide solution, the continuous layer structure of the fiber surface was disrupted and formed a discontinuous layer structure, the surface of the fibers became rougher, the specific surface area increased, and the inner tubular structure was exposed. Hence, the fibers could absorb more oil and improve the effect of the modification of asphalt. This is because the waxy layer and pectin on the surface of the corn stalks were removed after the chemical treatment.

As can be seen from Figure 15, the diameters of the lignin fibers were uneven. Because the lignin fiber material itself has a low density and exhibits a flocculent shape, if an excessive number of lignin fibers are incorporated into asphalt, uneven agitation and uneven distribution of the lignin fibers may occur. It can be seen from Figure 16 that the basalt fibers had the highest aspect ratio. However, because the surface of basalt fibers is very smooth, their ability to absorb oil is the worst in comparison with lignin and corn stalk fibers. Therefore, the corn stalk fibers enable more uniform mixing than the lignin fibers and have a better oil absorption effect than the basalt fibers. 

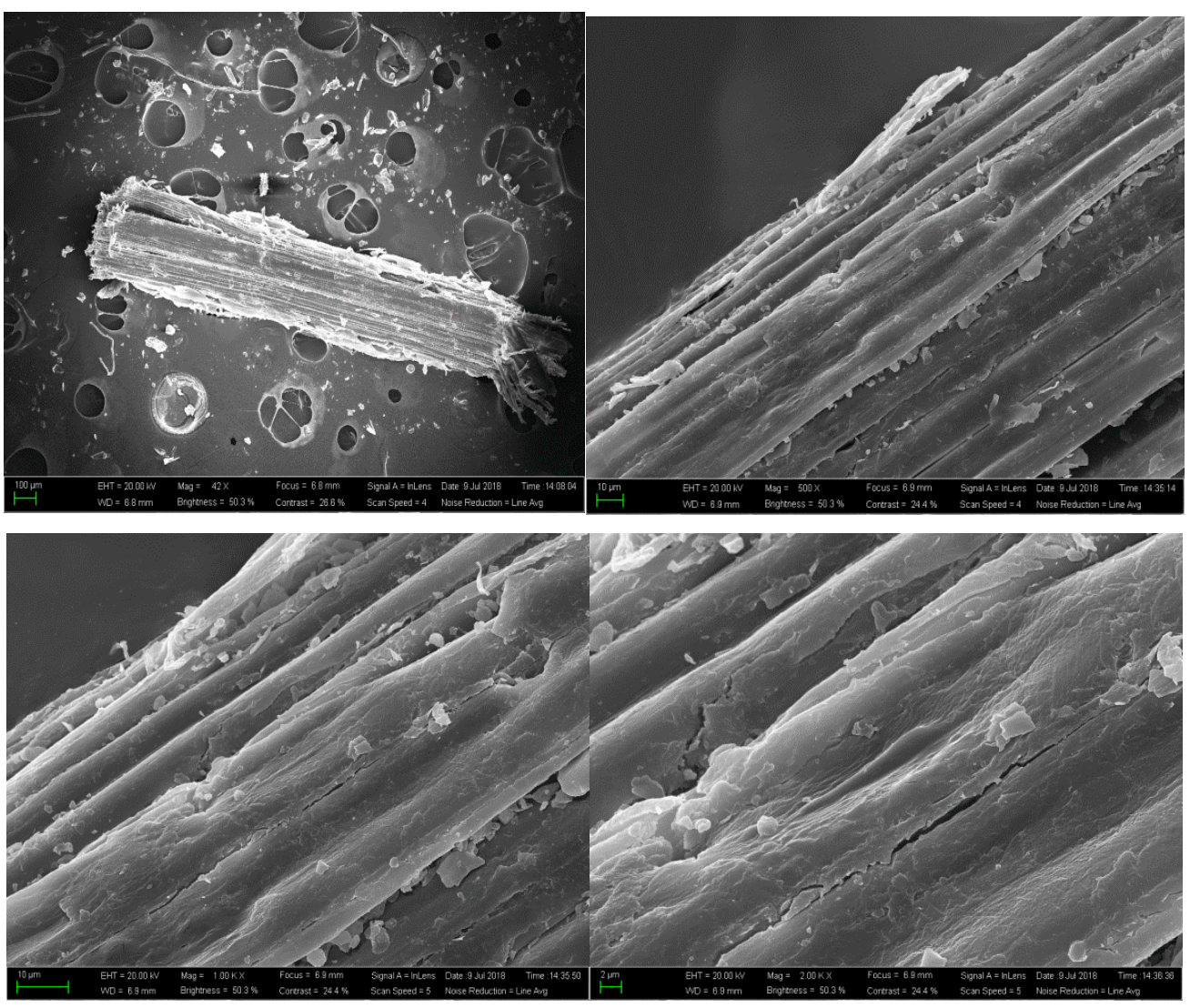

Figure 13. Corn stalk fibers without chemical treatment.
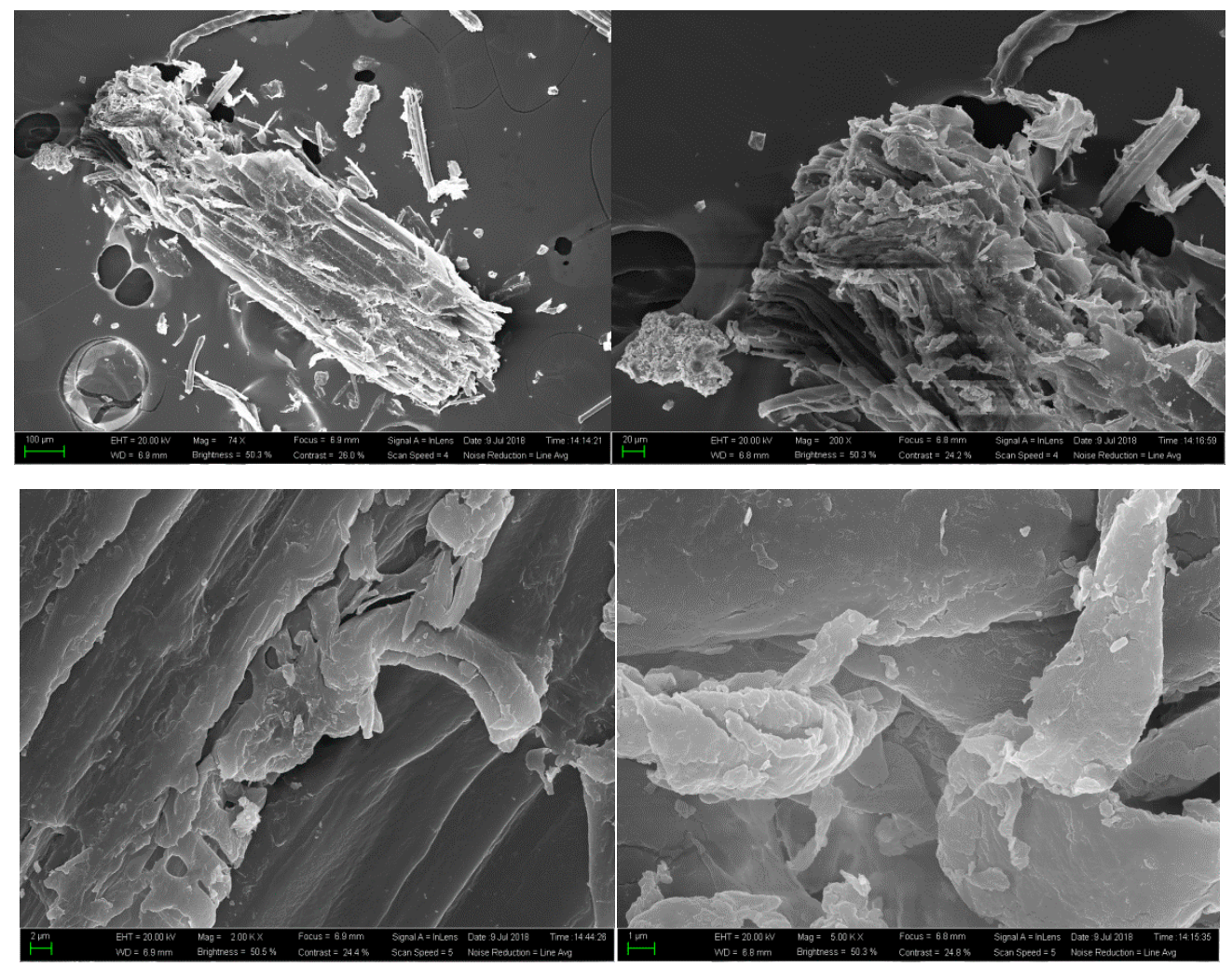

Figure 14. Corn stalk fibers after chemical treatment. 


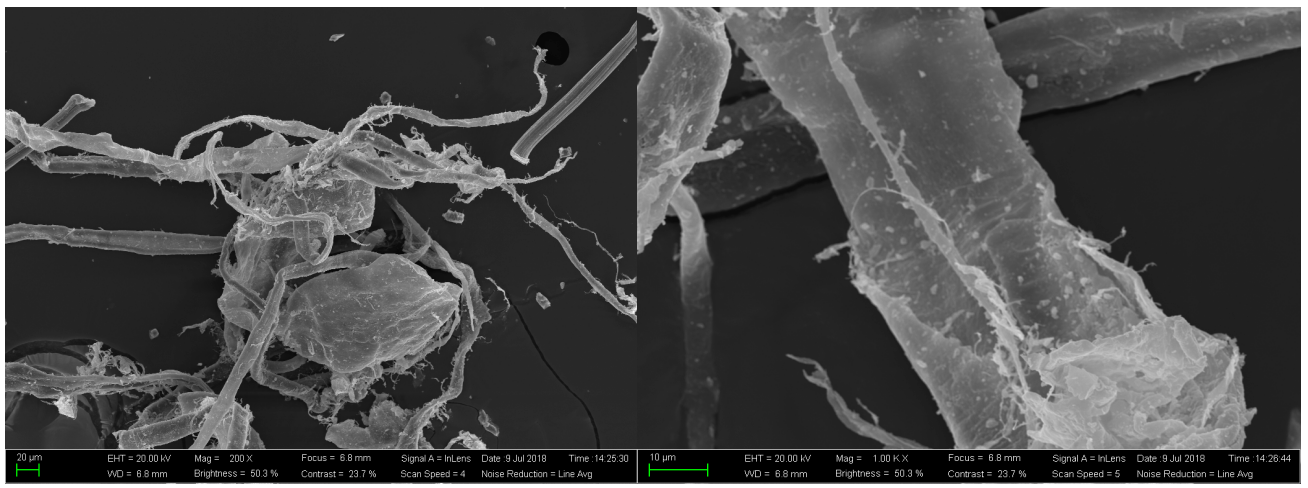

Figure 15. Lignin fibers.
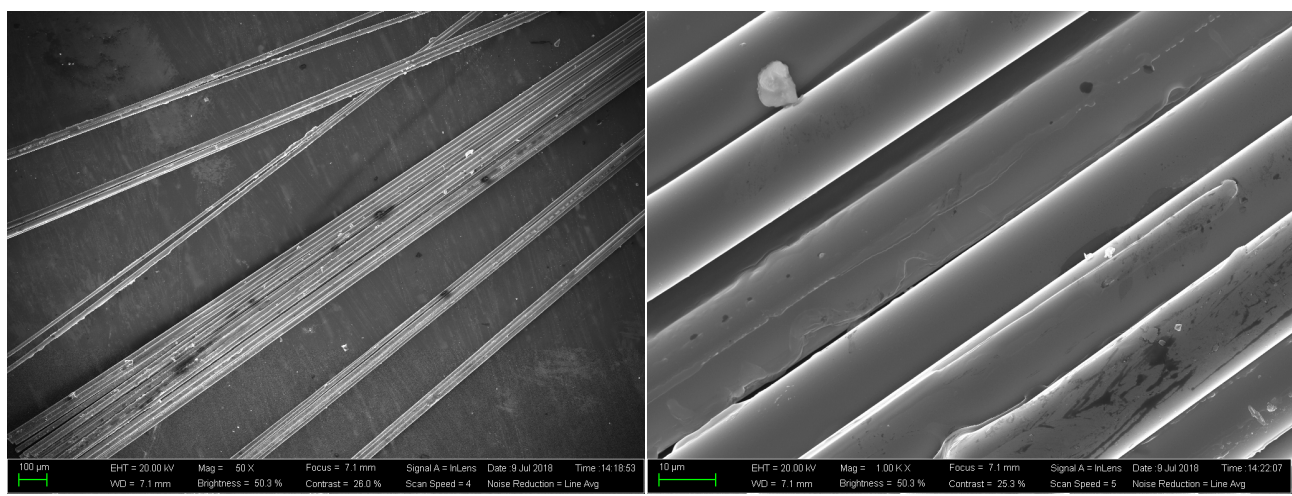

Figure 16. Basalt fibers.

\subsection{Fiber Heat Resistance}

It is generally recommended that the fibers are dry-mixed with the aggregate for $15 \mathrm{~s}$ in the preparation of a hot-mix asphalt mixture and then sprayed into the asphalt for wet mixing. For ordinary asphalt, the temperature at which the fibers are mixed with the aggregate can reach $170-180^{\circ} \mathrm{C}$, whereas it may exceed $200^{\circ} \mathrm{C}$ for modified asphalt. The temperature of an ordinary asphalt mixture can reach $150-170^{\circ} \mathrm{C}$, whereas the temperature of a styrene/butadiene/styrene-modified asphalt mixture is generally around $180^{\circ} \mathrm{C}$ [22]. Therefore, the fibers are required to have a certain thermal stability so as to ensure that they do not cause a significant decrease in performance during the mixing, transportation, and pavement construction processes. The percentage mass loss of the fibers is shown in Figure 17.

According to the test data, the decline in the quality of the corn stalk fibers without chemical treatment was very serious. During the test, a combustion phenomenon occurred with the corn stalk fibers that were not chemically treated. Most of the internal components of the fibers decomposed into gases or liquids, which evaporated at high temperatures. Finally, the fibers were carbonized to form ash (Figure 18). After chemical treatment, the percentage mass loss of the corn stalk fibers was $6 \%$, whereas the percentage mass loss of the untreated stalk fibers was about 15 times greater than that of the treated fibers, and the thermal stability of the chemically treated fibers greatly improved. This is because components with a low thermal stability, such as amino acids, proteins, and some hemicellulose, etc., were removed from the fibers in the process of treatment with the alkaline solution. From Figures 19 and 20, it can be seen that the color of both the lignin fibers and the corn stalk fibers became yellowish-brown after heating. This is mainly because lignin fibers are organic fibers that are extracted from wood and other plant materials, and the composition of lignin fibers is similar to that of corn stalk fibers. Basalt fibers are a new type of inorganic environmentally protective high-performance fiber material, which is composed of $\mathrm{SiO}_{2}, \mathrm{Al}_{2} \mathrm{O}_{3}, \mathrm{CaO}, \mathrm{MgO}, \mathrm{Fe}_{2} \mathrm{O}_{3}, \mathrm{TiO}_{2}$, and other oxides. A basalt fiber is a continuous fiber that is obtained by the rapid drawing of basalt stone material at a high 
temperature of $1450-1500{ }^{\circ} \mathrm{C}$ and has very high resistance to high temperatures [23]. The percentage mass loss of basalt fibers was $0.2 \%$ (Figure 21 ). Therefore, the results of the fiber heat resistance test show that the basalt fibers exhibited the best heat resistance, and the heat resistances of the lignin fibers and corn stalk fibers did not differ greatly.

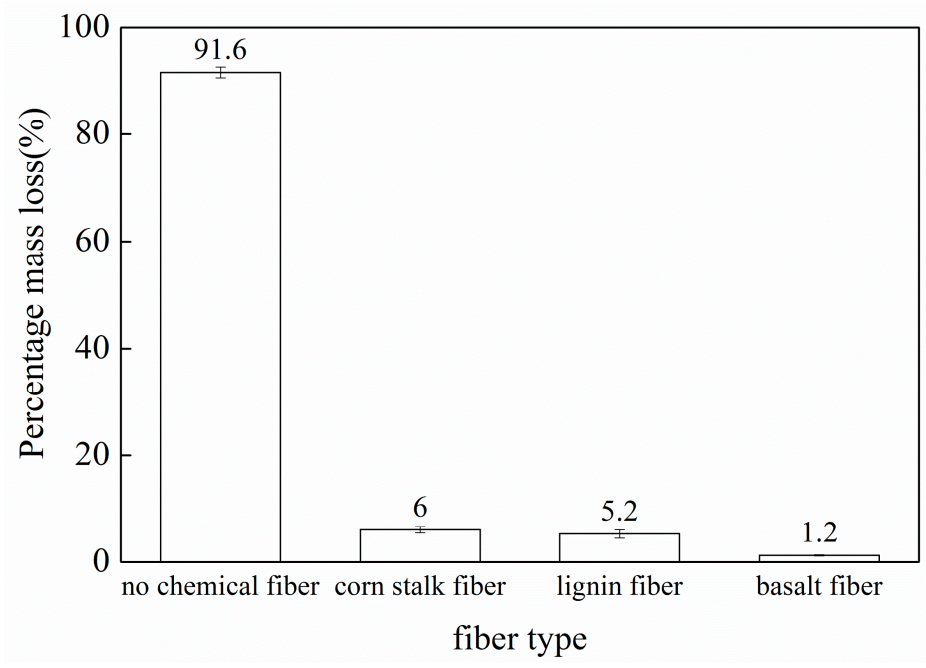

Figure 17. Percentage mass loss of the fibers.

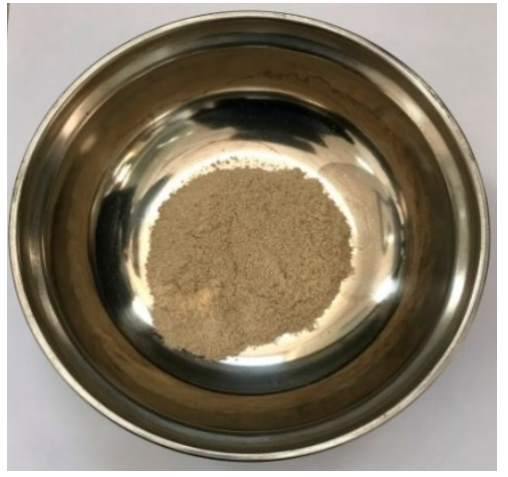

(a)

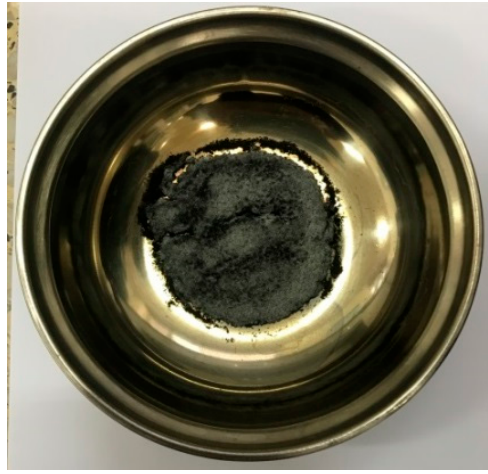

(b)

Figure 18. Corn stalk fibers without chemical treatment. (a) before heating, (b) after heating.

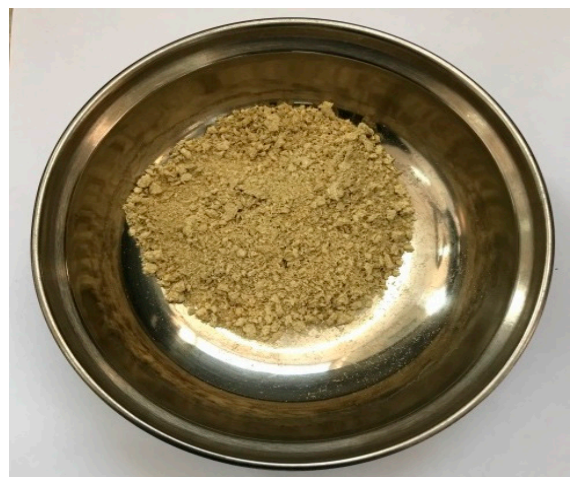

(a)

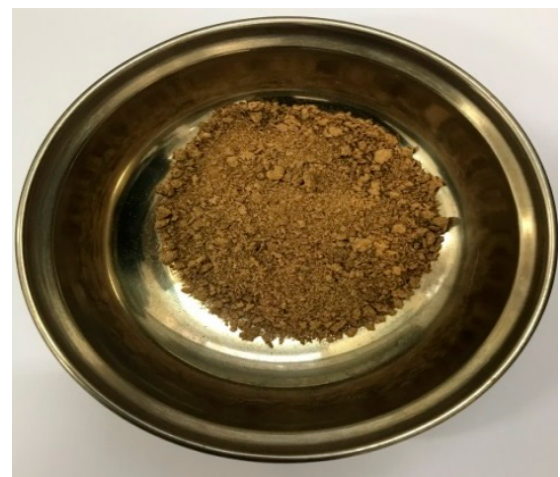

(b)

Figure 19. Corn stalk fibers after chemical treatment. (a) before heating, (b) after heating. 


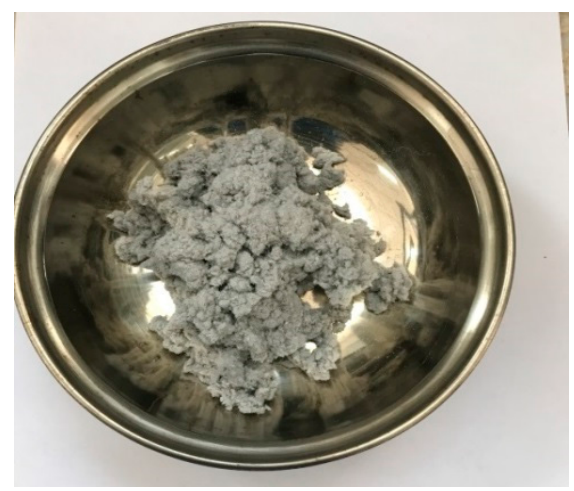

(a)

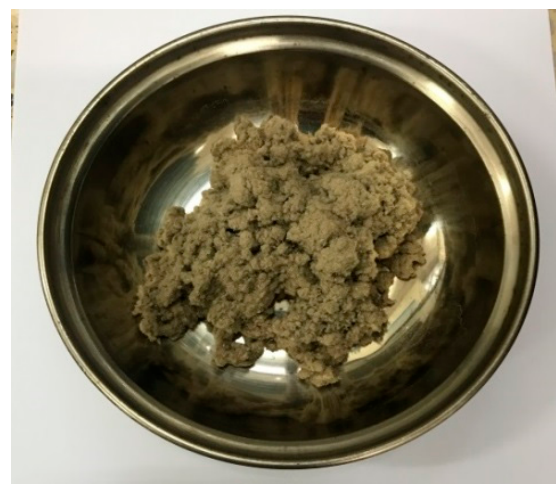

(b)

Figure 20. Lignin fibers. (a) before heating, (b) after heating.

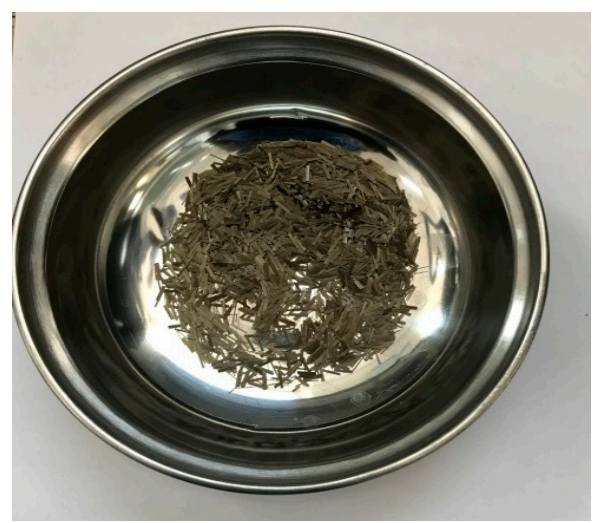

(a)

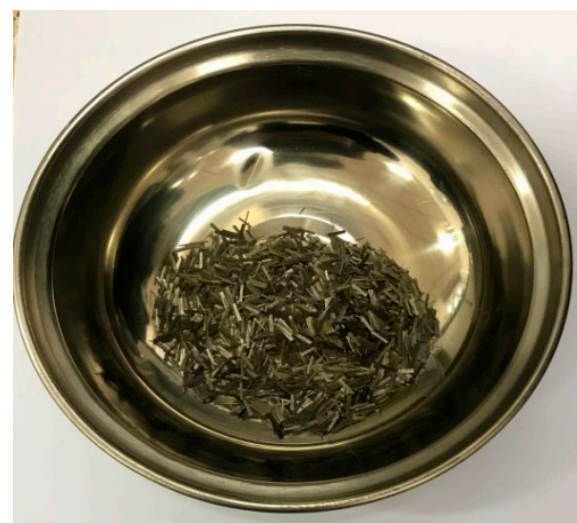

(b)

Figure 21. Basalt fibers. (a) before heating, (b) after heating.

It can be seen from Figures 22 and 23 that the pyrolysis of corn stalk fibers can be roughly divided into a water removal stage, a preheating stage, the main stage of thermal decomposition, and a stage of slow decomposition of the residue. The first stage is a stage of dehydration and drying, which is mainly due to the release of internal water from the fibers, including physically and chemically adsorbed water [24]. The second stage is a preheating stage. The internal structures of the fibers decompose into free radicals and major functional groups and release small amounts of volatile small-molecule gases, such as carbon dioxide and carbon monoxide. The third stage is a stage of rapid pyrolysis. The thermogravimetric analysis curves display a rapid decline, and it can be seen from the figures that the fibers lost about $70 \%$ of their weight. This is the most significant temperature range for the pyrolysis of corn stalk fibers and ends at about $360^{\circ} \mathrm{C}$. The pyrolysis processes of organic components such as cellulose, hemicellulose, and lignin in corn stalk fibers are superimposed on one another, but the main temperature regions of the thermal decomposition of these components are different [25]. It is generally believed that the most unstable hemicellulose in the composition begins to decompose at about $150{ }^{\circ} \mathrm{C}$, which destroys the linkages between cellulose, hemicellulose, and lignin [26]. As the temperature increases, the weight loss rate of the fiber increases, and the reaction rate increases and reaches a maximum at about $340^{\circ} \mathrm{C}$. This shows that cellulose begins to decompose in large quantities. Because lignin is more difficult to pyrolyze, its decomposition process spans almost the entire temperature range of pyrolysis. The fourth stage involves slow decomposition of the residue, which mainly produces carbon and ash, and hence is also a stage of carbonization. In this temperature range, lignin continues to decompose and a large amount of volatile gases are generated [27]. 


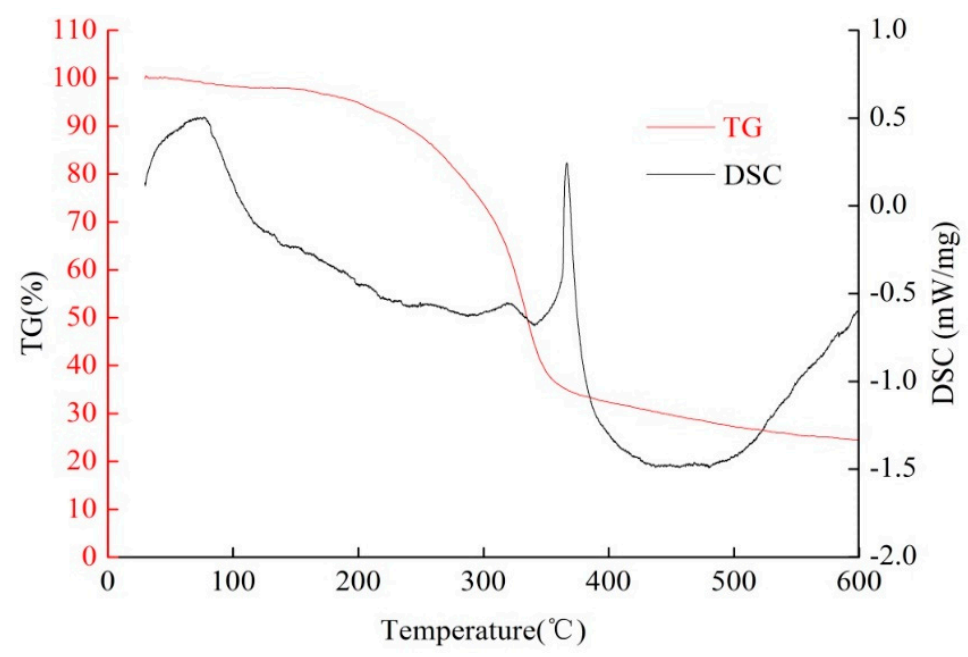

Figure 22. Thermogravimetric analysis (TG) and differential scanning calorimetry (DSC) curves for corn stalk fibers without chemical treatment.

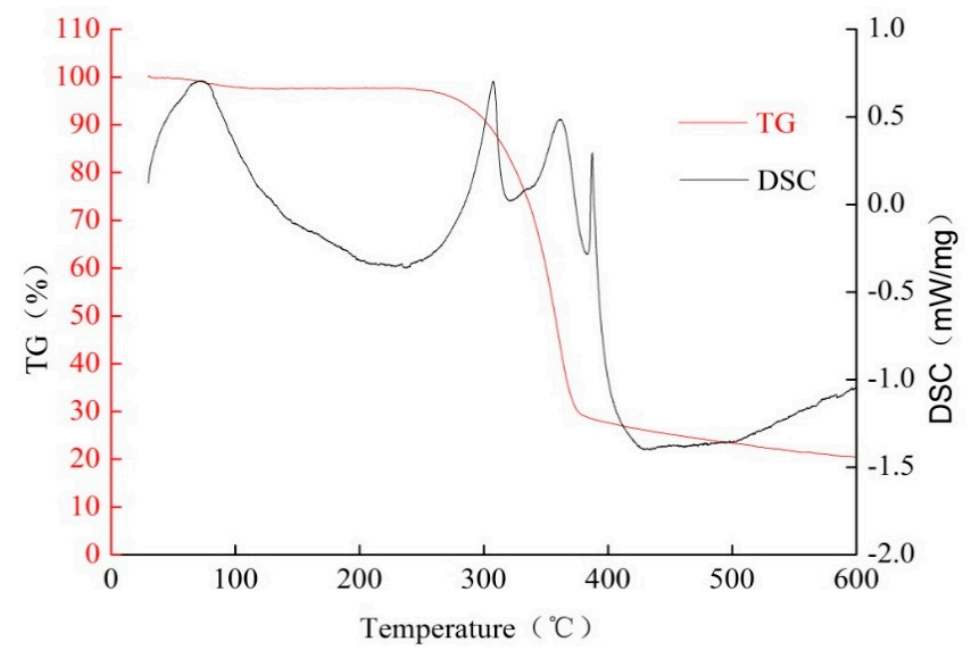

Figure 23. TG and DSC curves for corn stalk fibers after chemical treatment.

However, the thermal stability of the treated corn stalk fibers was higher than that of the untreated corn stalk fibers. In addition, the treated fibers began to undergo rapid pyrolysis at $260^{\circ} \mathrm{C}$. The untreated fibers were gradually pyrolyzed from room temperature and began to undergo rapid pyrolysis at $200^{\circ} \mathrm{C}$. This shows that most of the hemicellulose and components with a low thermal stability in the fibers were removed by the sodium hydroxide solution and the thermal stability of the fibers was greatly improved, and they can be used in the construction of asphalt pavements.

\subsection{Hygroscopicity of Fibers}

Water damage to asphalt mixtures has always been an important issue that limits the performance and durability of asphalt pavements [28]. However, if fibers are added to a mixture, the absorption of water by the fibers will inevitably affect the overall performance of the asphalt mixture. It is generally required that the hygroscopicity of the fibers should be as low as possible, because if a fiber has low hygroscopicity this indicates that it has higher resistance to water erosion. In addition, the probability of contact between the asphalt mixture and water is reduced, and the probability of phenomena such as looseness, peeling, and pits on the surface of the asphalt pavement will also decrease, which will thereby prolong the service life of the asphalt pavement [29]. On the other hand, if fibers have higher hygroscopicity, this means that fibers stored in ambient conditions can absorb moisture and thus deteriorate easily. This will seriously affect the dispersion and uniformity of the fibers 
when they are added to the asphalt mixture. Therefore, attention should be paid to the arrangement of moisture-proofing and dehumidification when preserving the fibers. The hygroscopicity of the fibers in this study is shown in Table 9.

According to the test results, the water contents of the lignin fibers and corn stalk fibers were $3.8 \%$ and $3.6 \%$, respectively, whereas the water content of the basalt fibers was $0.1 \%$. In the moisture absorption test, the moisture absorption rate of the corn stalk fibers was the highest (24.4\%), followed by that of the lignin fibers $(17.8 \%)$, and the moisture absorption rate of the basalt fibers was the lowest $(1.6 \%)$. The test results show that corn stalk fibers absorbed more moisture than lignin and basalt fibers because of their internal pores and rough surface, and hence they need to be stored in a cool and dry place or dried before use.

Table 9. Hygroscopicity of fibers.

\begin{tabular}{ccc}
\hline Fiber Type & Water Content (\%) & Moisture Absorption Rate (\%) \\
\hline Corn stalk fiber & 3.6 & 24.4 \\
Lignin fiber & 3.8 & 17.8 \\
Basalt fiber & 0.1 & 1.6 \\
\hline
\end{tabular}

\subsection{General Performance Index of Fibers}

As an additive for asphalt mixtures, the reinforcing effect of fibers is closely related to their performance characteristics. Therefore, this study mainly used the physical properties of lignin fibers, basalt fibers, and corn stalk fibers for comparative analysis. Their physical properties will have a significant impact on the road performance of asphalt mixtures. Selected physical properties of the three kinds of fibers are presented in Table 10.

The lengths of the three kinds of fibers are given in Table 10 and were in the order of basalt fibers $>$ corn stalk fibers $>$ lignin fibers. The lengths of the fibers will directly affect the strength of the asphalt mixture and its workability during construction mixing. If the lengths of the fibers increase, the strength of the asphalt mixture will also increase. However, if the fibers are too long, they will be easily knotted during the mixing process of the asphalt mixture, and an even distribution and dispersibility of the fibers will be difficult to achieve. The fibers in this case will not only fail to enhance the strength of the asphalt mixture, but also affect the workability of the mixture. The melting temperatures of the three fibers exceeded $200{ }^{\circ} \mathrm{C}$ and were thus higher than the usual maximum temperature $\left(180^{\circ} \mathrm{C}\right)$ for the mixing of the asphalt mixture. Therefore, these fibers meet the requirements for asphalt pavement.

Table 10. General performance index of fibers.

\begin{tabular}{cccc}
\hline Technical Indicator & Fiber Type & & \\
\hline & Corn stalk fibers & Lignin fibers & Basalt fibers \\
Fiber length $(\mathrm{mm})$ & $<3$ & $<2$ & 6 \\
Fiber diameter $(\mu \mathrm{m})$ & $50-425$ & - & 15.72 \\
Relative density $\left(\mathrm{g} / \mathrm{cm}^{3}\right)$ & 1.04 & 0.56 & 2.63 \\
Color & Golden & Gray & Gold-green \\
Melting temperature $\left({ }^{\circ} \mathrm{C}\right)$ & $>240$ & $>200$ & 1250 \\
\hline
\end{tabular}

\subsection{Performance of Fiber Asphalt}

To gain a clear conceptual understanding of the properties of corn stalk fiber asphalt, a comparison of the performance of corn stalk fiber asphalt, lignin fiber asphalt, basalt fiber asphalt is given in Table 11.

According to the test data, the rutting factors of the fiber asphalts gradually increased with an increase in the mass percentage of corn stalk fibers incorporated. When the mass percentages of corn 
stalk fibers were $8 \%$ and $10 \%$, the rutting factors of corn stalk fiber asphalt at $76{ }^{\circ} \mathrm{C}$ were 0.57 and 0.637 , respectively, which show that corn stalk fibers had a better effect in terms of modifying the asphalt. At the same temperature, the rutting factors increased with an increase in the mass percentage of corn stalk fibers, and, when this percentage reached $10 \%$, the modifying effect of the corn straw fibers on the asphalt exceeded that of the lignin fibers. This shows that the mixing of the corn stalk fibers was uniform and no phenomenon of fiber clustering occurred, even when the mass percentage of corn stalk fibers was excessive. According to the experimental data, the rutting factors of lignin fiber asphalt increased initially and then decreased with an increase in the mass percentage of lignin fibers. This is because the lignin fibers had a lower density and a larger volume in comparison with the other fibers at the same mass percentage. Therefore, after the addition of an excessive amount of lignin fiber to asphalt, its modifying effect on the asphalt is unsuitable, owing to uneven mixing and dispersion of the fibers. For basalt fibers, the rutting factors of fiber asphalt slowly increased and the growth rate gradually decreased with an increase in the mass percentage of the fibers. This is because basalt fibers have a smoother surface than the other types of fibers and thus have a weaker ability to absorb asphalt. Owing to the great length of basalt fiber, too many fibers are added to asphalt to easily affect the performance of the fiber-modified asphalt.

Table 11. Rutting factors of different fiber asphalts.

\begin{tabular}{ccccc}
\hline Type no. & Fiber Type & \multicolumn{3}{c}{ Rutting Factor (kPa) } \\
\hline & & \multicolumn{3}{c}{ Temperature $\left({ }^{\circ} \mathrm{C}\right)$} \\
& & 70 & 76 \\
\hline 1 & & 1.238 & 0.616 & \\
2 & & 1.706 & 0.861 & \\
3 & Corn stalk fiber & 1.889 & 0.967 & 0.57 \\
4 & & 2.089 & 1.047 & 0.637 \\
5 & & 2.419 & 1.188 & \\
\hline 6 & & 1.5 & 0.753 & 0.676 \\
7 & Lignin fiber & 2.205 & 1.197 & \\
8 & & 2.034 & 1.16 & 0.659 \\
\hline 9 & & 1.351 & 0.694 & \\
10 & \multirow{2}{*}{ Basalt fiber } & 1.32 & 0.696 & \\
11 & & 1.496 & 0.751 & \\
12 & & 1.585 & 0.811 & \\
\hline
\end{tabular}

\subsection{Performance of Asphalt Mixtures}

The results of the Marshall test for five different kinds of SMA-13 fiber asphalt mixtures are shown in the Table 12.

As can be seen from Table 12, the stability of the SMA-13 asphalt mixture after the addition of fibers was improved. The stability of SMA-13 asphalt mixture with $0.3 \%$ lignin fibers was slightly higher than that of SMA-13 asphalt mixture with the same amount of corn stalk fibers, and with the increase of corn stalk fiber content, the stability of corn stalk fiber SMA-13 asphalt mixture was gradually increasing. This is because the fiber asphalt binder had a higher modulus and viscosity than the neat asphalt, thereby increasing the frictional resistance between the aggregates and effectively preventing the particle movement of the aggregate. Therefore, the high-temperature stability of the SMA mixture after fiber addition was more significantly increased.

In order to investigate the moisture damage resistance of fiber-modified asphalt mixtures, indirect tensile strength at $15^{\circ} \mathrm{C}$ and immersion Marshall tests were also conducted, which can be found in Table 13. It is clear that adding both of lignin and corn stalk fibers into SMA asphalt mixtures can increase the indirect tensile strength. This showed that in the asphalt mixture, the fiber adsorbed the asphalt to form a lap joint structure, thereby playing the role of reinforcement and bridging. 
However, with the increase of corn stalk fiber content, the indirect tensile strength of SMA-13 asphalt mixture decreased, which indicated that the modified effect of corn stalk fiber on asphalt was greater than the reinforcement effect of fiber on mixture. Therefore, adding an appropriate amount of corn stalk fiber in asphalt mixture was beneficial to improve the tensile crack resistance of the asphalt mixture.

Table 12. The Marshall test results of SMA-13 asphalt mixture.

\begin{tabular}{|c|c|c|c|c|c|c|c|c|}
\hline Mixture Type & $\begin{array}{c}\text { Fiber Content } \\
(\%)\end{array}$ & $\begin{array}{l}\text { Asphalt Stone } \\
\text { Ratio (\%) }\end{array}$ & $\begin{array}{l}\text { Gross Volume } \\
\text { Density }\left(\mathrm{g} / \mathrm{cm}^{3}\right)\end{array}$ & VV (\%) & VMA (\%) & VFA (\%) & $\begin{array}{l}\text { Stability } \\
(\mathrm{kN})\end{array}$ & $\begin{array}{c}\text { Flow Value } \\
(0.1 \mathrm{~mm})\end{array}$ \\
\hline No blending & 0 & 5.6 & 2.406 & 3.33 & 20.1 & 82.4 & 8.78 & 27.5 \\
\hline $\begin{array}{l}\text { Adding lignin } \\
\text { fiber }\end{array}$ & 0.3 & 5.8 & 2.367 & 3.56 & 21.4 & 81.7 & 9.71 & 31.4 \\
\hline $\begin{array}{l}\text { Adding corn } \\
\text { stalk fiber }\end{array}$ & 0.3 & 5.8 & 2.371 & 3.60 & 21.9 & 80.5 & 9.68 & 33.5 \\
\hline $\begin{array}{l}\text { Adding corn } \\
\text { stalk fiber }\end{array}$ & 0.6 & 6.0 & 2.358 & 3.62 & 22.1 & 80.7 & 9.87 & 26.5 \\
\hline Specification & - & - & - & $3 \sim 4$ & $\geq 17$ & $75 \sim 85$ & $\geq 6$ & - \\
\hline
\end{tabular}

Table 13. The Spitting and immersion Marshall test results of SMA-13 asphalt mixture.

\begin{tabular}{ccc}
\hline Mixture Type & Spitting Strength (kN) & Residual Stability (\%) \\
\hline No blending & 11.3 & 83.4 \\
Adding 0.3\% lignin fiber & 13.5 & 87.3 \\
Adding 0.3\% corn stalk fiber & 15.6 & 86.9 \\
Adding 0.6\% corn stalk fiber & 14.6 & 87.7 \\
Adding 0.9\% corn stalk fiber & 12.3 & 88.2 \\
Specification & - & $\geq 80$ \\
\hline
\end{tabular}

It can be also seen from Table 13 that the residual Marshall stability of the SMA-13 asphalt mixtures added with the fiber was improved. The residual stability of SMA-13 asphalt mixture with $0.3 \%$ lignin fiber was similar to that of SMA-13 asphalt mixture with the equivalent amount of corn stalk fiber. In general, adding lignin and corn stalk fibers can help to improve the moisture damage resistance of SMA mixtures. It can be also found from Table 13 that adding more corn stalk fiber could increase the moisture damage resistance of SMA mixtures.

\section{Economic Analysis and Industrial Aspects of Corn Stalk Fibers}

As discussed above, corn stalk fibers in the laboratory exhibited comparable performance to lignin fibers, which implies that corn stalk fibers are a promising substitute for traditional fibers in asphalt pavement applications. However, it is necessary and meaningful to conduct an economic analysis of a new material for it to achieve practical utilization. The market prices of the experimental materials from a local dealer are listed in Table 14.

Hence, according to the optimized production process, the total costs of the preparation of a certain mass of the corn stalk fiber product can be calculated and are shown in Table 15.

The results show that it costs $0.1440 \mathrm{RMB}$ to prepare $96 \mathrm{~g}$ of the corn stalk fiber product, and the unit price of corn stalk fibers is about $1500 \mathrm{RMB} /$ tonne in China (Table 16). Previous studies have shown that corn stalk fibers are inferior to lignin fibers and basalt fibers in their modifying effect on asphalt when the same mass percentages of fibers are blended with asphalt. However, corn stalk fibers have very good prospects as a new material for asphalt pavement applications from the perspectives of uniform mixing of the fibers with asphalt and efficient use of crop waste, and they are also cheaper than the two other types of fibers. Not only the conservation of limited resources such as basalt fiber pavement materials, but also the treatment of agricultural waste in the form of corn stalks is of great significance to the future development of China. Therefore, owing to the low price of corn stalk fibers and their significant environmental advantages, corn stalk fiber materials will hopefully become used in asphalt pavement to replace lignin fibers. 
The physical and chemical methods for the preparation of corn stalk fibers proposed in this paper are easily carried out in laboratory research, because a rind-pith separation instrument, a WKF250 crusher, and a high-speed multifunctional crusher are sufficient for carrying out the physical methods, and a constant-temperature magnetic stirrer is sufficient for the chemical reaction. In fact, these instruments are common in agriculture and daily life, and the chemical reagent, namely, sodium hydroxide particles, is easily obtained. Therefore, the preparation of corn stalk fibers using the abovementioned physical and chemical methods is easily achieved from an industrial point of view. It is worth mentioning that because a small proportion of fibers are lost during the polishing of corn stalk fibers and chemical pretreatment cleaning, it is difficult to collect and weigh all the fiber products. However, about $24 \mathrm{~g}$ of the product can be collected in a single production cycle. An increase in the volume of the reaction vessel can be expected to reduce the fiber mass loss. In addition, more studies are still needed to optimize the whole production process. Finally, the price of corn stalk fiber is only predicted through laboratory tests, and the price of corn stalk fiber which was industrially produced will change.

Table 14. Market prices of the experimental materials from a local dealer.

\begin{tabular}{cc}
\hline Material & Market Price (RMB/tonne) \\
\hline Sodium hydroxide & 4000 \\
Corn stalks & 130 \\
Water & 5.6 \\
\hline
\end{tabular}

Note: 1 RMB roughly equals 0.16 USD.

Table 15. Economic analysis of the preparation of corn stalk fibers.

\begin{tabular}{cc}
\hline Product & Price (RMB) \\
\hline Sodium hydroxide particles (96 g, fiber: sodium hydroxide $=4.8: 1)$ & 0.08 \\
Water (4000 g, sodium hydroxide: water $=1: 200)$ & 0.0224 \\
Corn stalks (320 g, corn stalks: fiber $=100: 30)$ & 0.0416 \\
Unit cost of produced corn stalk fibers $=1500 \mathrm{RMB} /$ tonne & \\
\hline
\end{tabular}

Table 16. Market prices of the fibers for asphalt pavement applications.

\begin{tabular}{cc}
\hline Fiber Type & Price (RMB/tonne) \\
\hline Corn stalk fiber & 1500 \\
Lignin fiber & 4300 \\
Basalt fiber & 16000 \\
\hline
\end{tabular}

\section{Conclusions and Recommendations}

This paper introduced physical and chemical methods for preparing corn stalk fibers, and the corresponding optimal production process of corn stalk fibers was investigated. On the basis of the results that are presented, several conclusions can be drawn:

(1) Corn stalks from agricultural waste can be used to prepare corn stalk fibers, in which a physical method is used to form corn stalks into a fiber shape, and a chemical method enables the corn stalk fibers to meet the standards of asphalt pavement applications;

(2) The optimal process for the preparation of corn stalk fibers comprises initially separating the rind of corn stalks from the pith, and then crushing the corn stalk rind and comminuting it for $3.5 \mathrm{~min}$. Next, the corn stalk fibers are immersed in a sodium hydroxide solution with a concentration of $0.5 \%$ and reacted at $80^{\circ} \mathrm{C}$ for $30 \mathrm{~min}$. Here, the mass ratio of corn stalk fibers, sodium hydroxide, and water is 8:1:200; 
(3) The results of tests of the performance of the corn stalk fiber materials show that the corn stalk fibers obtained by the abovementioned physical and chemical methods meet the requirements of asphalt pavement applications and may be suitable for modifying asphalt;

(4) As to the SMA-13 asphalt mixtures, the service performance can be well improved when adding the corn stalk fiber. Therefore, corn stalk fiber can have the potential to replace the lignin fiber in asphalt mixture.

(5) An economic analysis shows that in comparison with lignin fibers and basalt fibers, the produced corn stalk fibers are not only cheaper but also effectively reduce the pollution of the environment by corn stalk waste. They can be used as a substitute for limited resources and a more environmentally friendly asphalt pavement fiber material.

On the basis of the research presented above, here are some recommendations for future study:

(1) The optimal process for the preparation of corn stalk fiber was carried out on a laboratory scale in this study. If corn stalk fibers are to be industrially mass-produced, more research is needed to optimize the production method to ensure the performance of the fibers. Sewage treatment in the chemical production of corn stalk fibers also needs to be considered and studied;

(2) More research is needed into the mechanism of the modification of asphalt by corn straw fiber materials. More evaluation indices and test methods should be adopted for measuring other aspects of the performance of corn stalk fiber asphalt, such as the low-temperature cracking resistance performance, adhesion and cohesion performance, and so on;

(3) The road performance of corn stalk fibers after being mixed with the asphalt mixture should be studied to ensure its effectiveness in an actual application.

Author Contributions: Data curation, Z.C. (Zining Chen); Formal analysis, J.Y.; Investigation, Z.C. (Zining Chen); Methodology, J.Y.; Project administration, J.Y., Z.C. (Zhiguo Chen) and D.F.; Resources, Z.C. (Zhiguo Chen); Supervision, D.F.; Writing—original draft, Z.C. (Zining Chen); Writing—review \& editing, Z.C. (Zining Chen) and J.Y.

Funding: This research received no external funding and the APC was funded by Harbin Institute of Technology.

Acknowledgments: Thanks for the financial support by National Natural Science Foundation of China (Grant No. 51878229), and the Fundamental Research Funds for the Central Universities (Grant No. HIT. NSRIF. 2017043).

Conflicts of Interest: The authors declare no conflict of interest.

\section{References}

1. Zuo, X.; Wang, H.; Wang, Y.; Wang, L.; Jing, L.; Wang, D. Estimation and suitability evaluation of corn straw resources in china. Chin. J. Agric. Resour. Reg. Plan. 2015, 36, 5-10.

2. Li, C.L.; Zhang, J.J.; Dou, S.; Ren, Z.C. Dynamic change in amounts soil humic and fulvic acid during corn stalk decomposition. J. Jilin Agric. Univ. 2009, 31, 729-732.

3. Shi, T.; Liu, Y.; Zhang, L.; Hao, L.; Gao, Z. Burning in agricultural landscapes: An emerging natural and human issue in China. Landsc. Ecol. 2014, 29, 1785-1798. [CrossRef]

4. Lu, W.; Liu, R.H.; Chen, S.; Cai, W.F.; Tao, Y.W.; Yin, R.Z.; Mei, Y.F. Classification and comparison of physical and chemical properties of corn stalk from three regions in china. Int. J. Agric. Biol. Eng. 2014, 7, 98-106.

5. Blanco-Canqui, H.; Lal, R. Corn Stover Removal for Expanded Uses Reduces Soil Fertility and Structural Stability. Soil Sci. Soc. Am. J. 2009, 73, 418. [CrossRef]

6. Zhang, J.; Yuan, J.; Zhang, W.X.; Tu, F.; Jiang, Y.; Sun, C.Z. Anaerobic detoxification fermentation by rhodospirillum rubrum for rice straw as feed with moderate pretreatment. Prep. Biochem. Biotechnol. 2017, 48, 1-9. [CrossRef]

7. Coronado, M.; Montero, G.; Garcia, C.; Torres, R.; Vazquez, A.; Ayala, R.; Leon, J.; Perez, L.; Romero, E. Cotton stalks for power generation in Baja California, Mexico by SWOT analysis methodology. Energy Sustain. 2015, 1, 75-86.

8. Malik, A.; Mohapatra, S.K. Power generation using cotton stalk-derived producer gas in diesel engines. Energy Sources Part A Recover Util. Environ. Eff. 2016, 38, 2816-2822. [CrossRef] 
9. Feng, C.; Li, B.; Xu, H. An Alternating Direction Method Approach to Cloud Traffic Management. IEEE Trans. Parallel Distrib. Syst. 2017, 28, 1. [CrossRef]

10. Morea, F.; Zerbino, R. Improvement of asphalt mixture performance with glass macro-fibers. Constr. Build. Mater. 2018, 164, 113-120. [CrossRef]

11. Sanjay, M.; Madhu, P.; Jawaid, M.; Senthamaraikannan, P.; Senthil, S.; Pradeep, S. Characterization and properties of natural fiber polymer composites: A comprehensive review. J. Clean. Prod. 2018, 172, 566-581. [CrossRef]

12. Zhou, X.Y.; Zheng, F.; Li, H.G.; Lu, C.L. An environment-friendly thermal insulation material from cotton stalk fibers. Energy Build. 2010, 42, 1070-1074. [CrossRef]

13. Qin, L.; Qiu, J.; Liu, M.; Ding, S.; Shao, L.; Lü, S.; Zhang, G.; Zhao, Y.; Fu, X. Mechanical and thermal properties of poly(lactic acid) composites with rice straw fiber modified by poly(butyl acrylate). Chem. Eng. J. 2011, 166, 772-778. [CrossRef]

14. Nourbakhsh, A.; Ashori, A. Wood plastic composites from agro-waste materials: Analysis of mechanical properties. Bioresour. Technol. 2010, 101, 2525-2528. [CrossRef] [PubMed]

15. Ren, D.; Bai, X.; Liu, D.; Gong, Y.; Gao, Z.; University, S.A. Design and test on roller-teeth husking roller in rind-pith separation of corn stalks. Trans. Chin. Soc. Agric. Mach. 2018, 49, 93-99.

16. Luo, Z.; Li, P.; Cai, D.; Chen, Q.; Qin, P.; Tan, T.; Cao, H. Comparison of performances of corn fiber plastic composites made from different parts of corn stalk. Ind. Crop. Prod. 2017, 95, 521-527. [CrossRef]

17. Liu, D.J.; Tao, X.Z.; Gao, L.X. Dry corn stalk nutrient distribution and palatability selection. J. Shenyang Agric. Univ. 2009, 2, 740-743.

18. Xun, H.; Wang, D. Effects of internal factors on surface wettability of corn stalk rind. Int. J. Agric. Biol. Eng. 2015, 8, 77-83.

19. Tian, Q.; Fang, G.; Shen, K.; Liu, W.; Liang, L. Effect of different pretreatments on the enzymolysis properties of corn stalk. J. For. Eng. 2017, 2, 89-94.

20. Chai, W. The study on Preparation and mechanism of Fiber-based Oil Sorption Materials. Ph.D. Dissertation, Shanghai University, Shanghai, China, 2015.

21. Ramin, B.; Siamak, T. Influence of Polypropylene Length on Stability and Flow of Fiber-reinforced Asphalt Mixtures. Civ. Eng. J. 2016, 2, 538-545.

22. Roberts, F.L.; Mohammad, L.N.; Wang, L.B. History of Hot Mix Asphalt Mixture Design in the United States. J. Mater. Civ. Eng. 2002, 14, 279-293. [CrossRef]

23. Zeriouh, A.; Belkbir, L. Thermal decomposition of a Moroccan wood under a nitrogen atmosphere. Thermochim. Acta 1995, 258, 243-248. [CrossRef]

24. Lai, Y.H.; Lu, M.X.; Ma, C.Y.; Shi, M.H. Research on pyrolysis characteristics of agricultural residues under liner heating temperature. J. Combust. Sci. Technol. 2001, 7, 245-248.

25. Byrne, C.; Nagle, D. Carbonization of wood for advanced materials applications. Carbon 1997, 35, $259-266$. [CrossRef]

26. Tzeng, S.S.; Chr, Y.G. Evolution of microstructure and properties of phenolic resin-based carbon/carbon composites during pyrolysis. Mater. Chem. Phys. 2002, 73, 162-169. [CrossRef]

27. Morova, N. Investigation of usability of basalt fibers in hot mix asphalt concrete. Constr. Build. Mater. 2013, 47, 175-180. [CrossRef]

28. Liu, H.Y.; Dai, J.L. Effect of water level on moisture stability of asphalt mixture. J. Changan Univ. 2004, $24,18-21$.

29. Merusi, F.; Caruso, A.; Roncella, R.; Giuliani, F. Moisture Susceptibility and Stripping Resistance of Asphalt Mixtures Modified with Different Synthetic Waxes. Transp. Res. Rec. J. Transp. Res. Board 2010, 2180, 110-120. [CrossRef]

(C) 2019 by the authors. Licensee MDPI, Basel, Switzerland. This article is an open access article distributed under the terms and conditions of the Creative Commons Attribution (CC BY) license (http://creativecommons.org/licenses/by/4.0/). 